\title{
Les confraternités de l'abbaye de Stavelot-Malmedy
}

Philippe George

\section{Citer ce document / Cite this document :}

George Philippe. Les confraternités de l'abbaye de Stavelot-Malmedy. In: Bulletin de la Commission royale d'histoire. Académie royale de Belgique. Tome 161, 1995. pp. 105-169;

doi : https://doi.org/10.3406/bcrh.1995.1143

https://www.persee.fr/doc/bcrh_0001-415x_1995_num_161_1_1143

Fichier pdf généré le 21/02/2020 


\title{
Les confraternités de l'abbaye de Stavelot-Malmedy
}

\author{
par Philippe GEORGE \\ Université de Liège (1)
}

L'abbaye de Stavelot-Malmedy fut fondée en Ardenne septentrionale au milieu du VII ${ }^{e}$ siècle par saint Remacle, moine de Luxeuil et de Solignac. Deux monastères la composent, de part et d'autre d'une frontière diocésaine : l'un à Stavelot relève de l'évêché de TongresMaastricht-Liège et l'autre à Malmedy de l'archevêché de Cologne (2).

Lors d'une première enquête systématique, nous avons étudié le trésor des reliques de l'abbaye pendant tout l'Ancien Régime (3); au total, nous avons recensé 52 documents permettant l'identification des reliques des saints ; la plupart furent découverts au cours d'un inventaire des châsses et reliquaires de l'ancien diocèse de Liège, dans ses limites d'avant 1559, auquel nous travaillons depuis plusieurs années (4).

(1) C'est pour nous un plaisir de dédier cet article à Monsieur Michel Parisse, Professeur à l'Université de Paris I (Sorbonne); l'exposé qu'il présenta Cartographie des réformes monastiques lotharingiennes des $X^{e}$ et $X I^{e}$ siècles et les conclusions qu'il tira au colloque Echanges culturels et religieux en Lotharingie au Moyen Age, à Luxembourg en 1988 furent pour nous un enrichissement à l'origine de l'approfondissement de nos recherches (Cf. Cinquièmes Journées d'Etudes Lotharingiennes, PUBLICATIONS DE LA SECTION HistorioUE DE L'INSTTTUT GRAND DUCAL, Luxembourg, t. CV, 1991).

(2) Notre thèse de doctorat en Philosophie \& Lettres à l'Université de Liège (1994), Stavelot et Malmedy. Monachisme et hagiographie en Ardenne (VII-XIF siècles), sous la direction du Professeur Jean-Louis Kupper, traite de toutes les sources concernant l'abbaye ; nous avons jugé inutile d'y faire sans cesse référence puisqu'elle est encore inédite.

Les origines de Stavelot-Malmedy ont fait l'objet d'une communication au Colloque de la Commission internationale d'Histoire ecclésiastique comparée La christianisation des campagnes, Liège, 1994, dont le texte Saint Remacle, évangélisateur en Ardenne (ca. 650). Mythe et réalité, est sous presse dans le BULleTIN DE L'INSTITUT HistORIQUe BELGE DE ROME.

(3) Nos articles parus dans le Bulletin de la Commission Royale d'Histoire (t. CLIII, 1987, p. 65-108 et p. 127-179) ont été repris dans un ouvrage Les reliques de Stavelot-Malmedy. Nouveaux documents, Malmedy, 1989.

(4) Notre participation le 11 février 1995 aux travaux du Centre de Recherche sur l'Antiquité Tardive et le Haut Moyen Age de l'Université de Paris X - Nanterre, consacrés aux Trésors du Haut Moyen Age, nous a donné l'occasion de faire le point sur ces recherches. Notre communication Les routes de la foi en pays mosan (IVe-XVe siecles). Sources, Méthode et problématique, est sous presse dans les CAHIERS DU CENTRE et conjointement dans les Feuillets de la Cathédrale de LièGe, nº 18-20, 1995. 
Pour l'étude exhaustive de ce trésor, il fallait surtout s'efforcer d'expliquer les acquisitions successives de reliques et son enrichissement progressif. Si l'on peut quelquefois cerner avec précision le facteur humain à travers la personnalité mieux connue de certains abbés, il faut bien reconnaître que ce sont là des cas rares.

La demande de reliques, adressée en 1263-1268 par Solignac (5), avait retenu notre attention par le rappel qui y était fait de la confraternité unissant les deux abbayes.

Une confraternité est l'union spirituelle de deux établissements religieux dans la prière commune et réciproque pour les vivants et les morts. Elle permet aussi une entraide matérielle dont les modalités varient. Les confraternités apportent un témoignage concret des liens qui unissent deux établissements religieux. Nous nous sommes dès lors interrogé sur les transferts de reliques qui ont pu suivre le même chemin. C'est là un aspect très particulier d'échanges qu'auraient pu susciter ou favoriser ces associations, de manière parfois fortuite.

Cette hypothèse de départ (6) nous a conduit à une étude systématique du réseau de fraternités de Stavelot-Malmedy (7).

Visant d'abord un but religieux par l'association de prières, les fraternités ont favorisé le développement de toute une autre série d'avantages, relations économiques et culturelles au sens le plus large. Ainsi les réformes monastiques, le culte des saints, l'histoire de l'art vont y trouver matière à réflexion mais aussi l'histoire économique et les relations humaines en général (8). Nous avons été amené à établir

(5) HR 346 et 348, c'est-à-dire le numéro d'édition des actes dans Recueil des chartes de l'abbaye de Stavelot-Malmedy, éd. HALkin (J.) \& RolaND (C.-G.), Bruxelles, 2 tomes, 1909-1930 (CRH in- $4^{\circ}$ ). Nous abrégerons désormais ci-dessous sous cette forme (HR suivi du numéro) les références aux divers documents de ce recueil.

(6) Nous l'avions déjà formulée dans notre ouvrage sur les reliques de Stavelot-Malmedy, op. cit., note 30 p. 18.

(7) Notre étude a fait l'objet d'une communication au Congrès de la Fédération Archéologique et Historique de Belgique à Liège en 1992 (Cf. Actes, t. I, p. 160-161) mais sans publication.

Seuls quelques-uns des documents de fraternité ont été étudiés par JAKOBI (Fr.-J.), Wibald von Stablo und Convey (1098-1158) Benediktinischerabt in frühen Stauferzeit, Münster, 1979 (VERÓfF. DER Hist. KOMMISSION FUR WESTFALEN, t. X, Abhandl. zur Conveyer Geschichtsschreibung, t. V ), p. 260-266; nous les mentionnerons ci-dessous.

(8) On rappellera ici l'article pionnier de Dom BERLIERE (U.), Les fraternités monastiques et leur rôle juridique, ACAdemie Royale de BelgiQue, Classe des LeTtRes \& Des SCIENCES MORALES \& POLITIOUES, MÉmOIRES in- $8^{\circ}, 2^{\circ}$ série, t. IX, 1920, p. 3-26. 
progressivement une prosopographie générale des membres des deux monastères au Moyen Age. Enfin nous avons aussi relevé, sans prétendre à l'exhaustivité, les autres fraternités des établissements unis à Stavelot-Malmedy. La toile tissée par tous ces réseaux à travers l'Occident dessine une véritable géographie relationnelle.

Depuis longtemps l'érudition allemande, intéressée par la Societas et fraternitas a développé une grille de lecture du sujet (9); nous l'avons appliquée au cas de Stavelot-Malmedy.

On distingue les confraternités générales - passées entre communautés avec charge de réciprocité - et personnelles - entre un individu et une communáuté; notre dossier ne comporte que des confraternités générales.

Les confraternités de Stavelot-Malmedy au Moyen Age sont connues par différents types de sources :

I. les actes de confraternité : actes d'association qui explicitent les dispositions prescrites dans le cadre de l'accord de la confraternité. Nous en avons pour l'abbaye, mais aussi isolément pour chacun des deux monastères.

II. pour Stavelot seul, une liste d'associations simplement énumérative, transcrite au XIVe siècle, des églises unies par confraternité.

III. un dossier d'archives de l'époque moderne: à cette époque les confraternités se poursuivent ou sont renouvelées sans que l'on sache toujours de quand date la première conclusion des actes.

Enfin, il nous faut aussi mentionner, sans que l'on puisse attester l'existence ou non d'une confraternité suivie, la liste de moines de Sta-

(9) Nombreuses sont les publications de l'Ecole de Fribourg-Münster, e. a. SCHMID (K.) \& Wollasch (J.), Societas et fraternitas, Berlin-New York, 1975, et, Memoria. Der geschichtliche Zeugniswert des liturgischen Gedenkens im Mittelalter, sous la direction de SCHMID (K.), \& Wollasch (J.), Munich, 1984 (MÓNSTERSCHE MITTELALTER-SCHRIFTEN, t. XLVIII).

Pour la France, il faut essentiellement citer les travaux de Dom Hallinger (K.), Gonze-Kluny. Studien zu den monastischen Lebensformen und Gegensätzen im Hochmittelalter, Rome, 1950-1951 (STUdia ANSElmiana, 22-25), de Michel Parisse sur Gorze (Cf. infra) et de Jean-Loup LEMATrRe sur les documents nécrologiques français (Cr. infra et LematTre (J.-L.), Les confratemités de La Sauve-Majeure, REVUE HISTORIQUE DE BORDEAUX \& DU DEPARTEMENT DE LA GIRONDE, 1981, p. 5-34 et IDEM, Mourir a SaintMartial. La commémoration des morts et les obituaires à Saint-Martial de Limoges du XI' au XIII siècle, Paris, 1989). 
velot-Malmedy commémorés à Remiremont (10), et le passage d'un rollifer de Saint-Etienne de Caen à Stavelot en 1108 (11).

Obtenir une liste des fraternités de Stavelot-Malmedy est relativement aisé. Au cours des siècles, les moines eux-mêmes ont désiré les connaître de manière à les honorer. Notre étude recense ainsi les liens établis avec plus d'une soixantaine d'établissements religieux.

Par contre, le commentaire en est très difficile s'il se veut exhaustif. Outre la nécessité de retrouver l'origine des contacts, il faut donner le relevé exact des obligations contractées et en décrire l'essor. Recenser les fraternités, c'est aussi passer au crible toutes les sources susceptibles d'informations dans chaque établissement uni à Stavelot-Malmedy. Quand l'occasion nous en a été offerte, nous avons en plus relevé en notes les mentions d'autres fraternités conclues par ces établissements, et de la sorte nous posons à travers notre article de précieux jalons pour toute autre étude de confraternités. A l'origine, bien sûr, les reliques retenaient prioritairement notre attention, d'autres centres d'intérêt sont venus s'y greffer.

(10) Remiremont (France, Vosges).

Au folio $9 \mathrm{r}$ du Liber Memorialis de Remiremont (Rome, Bibl. AngelicA, Cod. 10 (IX' siècle)) se trouve une liste : Nomina fratrum Malmundarii et Stabulaus monasteriis. Cent noms de moines alignés sur trois colonnes, dans un décor d'arcatures. Editions: HR 283 ; Liber memorialis von Remiremont, éd. HLAWITSCHA (E.), SCHMID (K.) \& Tellenbach (G.), MGH, Libri Memoriales, n 1, 1970, p. XXVIII-XXIX, 14-15 et planche du folio 9 r.. Commentaires: Geuenich (D.), OeXle (O.-G.) \& Schmid (K.), Listen monastischer und geistlicher Gemeinschaften des früheres Mittelalters, Münich, 1989, p. 334338 (MUNSTERSCHE MITTELALTER-SCHRIFTEN, t. IL). Remiremont est unie par confraternité avec une cinquantaine d'abbayes dont les longues listes de moines figurent dans le Liber Memorialis (Cf. Boulard (M.-O.), Documents nécrologiques de l'abbaye de Remiremont. Présentation et édition des documents nécrologiques du manuscrit Nouv. Acq. 349 de la Bibliothèque Nationale de Paris, Nancy, 1982 ; LEMAITRE, Mourir à Saint-Martial, op. cit., p. 51-52).

Le martyrologe du XII ${ }^{c}$ siècle de Remiremont porte mention au 3 septembre : Natale sancti Remacli, episcopi et confessoris, et au 11 octobre : Salmundario (sic) monasterio natale sancti Quirini presbiteri et martyris, ubi corporetenus (sic) quiescit reliquieque et socionum eius (PARIS, Biblothèque nationale, Manuscrit Nouv. Acq. Lat. 349, d'après QuenTin (Dom H.), Les martyrologes du Moyen Age. Etude sur la formation du martyrologe romain, Paris, 1908, p. 239 et 242).

(11) Morin (G.), Un « rollifer» de Saint-Etienne de Caen à l'abbaye de Stavelot, (LEODIUM, t. III, 1904, p. 73-76). Les rouleaux des morts perpétuent la mémoire et les mérites d'un défunt d'une certaine importance ; le porteur du rouleau suit un itinéraire variable, de communauté en communauté, et pas spécialement selon une confraternité établie ; chaque établissement visité ajoute un titre (titulus) au rouleau (LEMAITRE, Mourir à SaintMartial, op. cit., p. 329 sv..). 


\section{LES ACTES DE CONFRATERNITE}

Rares sont les originaux de ces actes qui nous soient parvenus, aucun en tout cas dans le fonds d'archives de Stavelot-Malmedy; comme pour la plupart des documents de l'abbaye, ce sont les cartulaires qui en ont conservé une copie, et c'est plus souvent dans le fonds d'archives de l'établissement uni par fraternité que les éditeurs des chartes de l'abbaye, Halkin et Roland, ont retrouvé les documents qu'ils ont publiés. Ces actes revêtent généralement la forme diplomatique de la notice Notum sit (12).

L'association vaut soit pour l'abbaye dans sa globalité, soit pour l'un des deux monastères. Ces actes s'échelonnent sur un siècle environ, du début du XIIe au début du XIII ${ }^{e}$ siècle, mais il s'agit souvent de renouvellements de confraternité dont on ignore la date initiale. Ces chartes détaillent les avantages d'ordre matériel qu'entraîne la confraternité : assistance mutuelle dans les difficultés, règlement des conflits, hospitalité...

De prime abord, on peut être surpris de la brièveté des dispositions transmises. Rien d'étonnant pourtant, car les moines connaissent la fraternité et il leur paraît inutile d'en préciser la pratique, hormis des clauses particulières. Pour Corvey en 1147, comme pour Trèves en 1218 (13), les actes font allusion aux coutumes différentes suivies sur place, mais ici encore sans besoin de donner des détails. Dès lors, l'historien est démuni : pour l'étude du monachisme à Stavelot-Malmedy au Moyen Age, le handicap est en effet la perte des coutumiers qui révèleraient les usages suivis et la liturgie pratiquée.

Les avantages les plus souvent mentionnés par les actes de fraternité sont :

- le trentain (tricenarium), c'est-à-dire une série de trente messes à la mémoire du défunt à dire à raison d'une par jour, sans interruption de la série (14);

- l'officium generale, qui correspond à l'office solennel accompagné de la distribution d'une pitance (15); le mot vigilia représente l'office des défunts ;

(12) Cf. LemAître, Mourir a Saint-Martial, op. cit., p. 358 sv..

(13) Que fieri apud nos pro defunctis solent (HR 303).

(14) LEMAitre, Mourir à Solignac, op. cit., p. 391 sv..

(15) LEMAITRE (J.-L.), Répertoire des documents nécrologiques français, publié sous la direction de MAROt (P.), Paris, 1980 et suppléments 1 et 2 (RECUEIL DES Historiens DE LA FRANCE, publié par l'Académie des Inscriptions \& Lettres, Obituaires, 4 vol., Paris, 1980-1991, t. VII), t. I, p. 75-76. 
- le septain (septenarium), c'est-à-dire que pendant sept jours, l'office et la messe sont dits à l'intention du défunt (16).

Une distinction est parfois établie entre la commémoration des abbés et des moines; les premiers obtiennent le trentain, les seconds le septain. A Solignac une prébende (praebenda) est mentionnée, c'est-àdire la part de nourriture et de boisson attribuée pour le repas du moine selon la Règle de saint Benoît $(39,4$ et 40,3$)(17)$.

L'inscription dans le nécrologe est rarement mentionnée et les documents nécrologiques de Stavelot-Malmedy n'apportent aucun renseignement intéressant sur les confraternités générales (18). La récitation du psaume Verba mea (Ps. 5) est mentionnée à Prüm. Pour Saint-Maur la commémoration des moines associés se fait en novembre, sans doute le 2 novembre lors de la commémoration des défunts, usage clunisien remontant au $X^{\mathrm{e}}$ siècle, sinon pour Saint-Michel-en-Thićrache le 7 juillet et pour Reims le 18 octobre, c'est-à-dire à des dates établies selon l'usage des maisons (19).

Les clauses principales des actes concernent la mémoire des morts ou l'exil forcé ou volontaire des moines. La confraternité permet en effet aussi au moine de changer de communauté.

Wibald, par ses voyages et ses activités, est à l'origine de trois renouvellements de fraternités (20) - Solignac, Saint-Maur et Reims mais surtout Erlebald, son frère, pendant son abbatiat déploie une activité remarquable pour renouveler les fraternités anciennes et en

(16) Lemaltre, Mourir à Saint-Martial, op. cit., p. 189 et 389.

(17) LemaMTre, Les confraternités de la Sauve-Majeure, op. cit., p. 13.

(18) Nous avons retranscrit tous ces documents et espérons un jour les publier. Dans le nécrologe du manuscrit LoNDREs, BRITISH LIBRARY, Add. 18028 (fol. 121-211), nous avons relevé seulement la mention personnelle au 21 août de Gérard de Terrasson, abbé de Solignac ( +1147$)$, au 1er septembre de Guillaume Natalis, abbé de Saint-Laurent de Liège $(\dagger 1686)$, au 10 septembre de Conrad abbé de Laach $(\dagger 1194)$, et au 13 septembre de Drogon $(\dagger 1173)$ et Conrad $(\dagger 1474)$, abbés de Saint-Jacques de Liège, inscrits en 1650. Ce manuscrit est le Livre du Chapitre constitué au début du XVIe siècle et utilisé jusqu'au $\mathrm{XIX}^{\mathrm{e}}$. Ces personnages sont identifiés respectivement dans LEMAiTRE (J.-L.), Les documents nécrologiques de l'abbaye Saint-Pierre de Solignac, publiés sous la direction de P. Marot, avec la collaboration de J. Dufour, Paris, 1984 (RecueIl Des Historiens de LA FRANCE, publié par l'Académie des Inscriptions \& des Belles-Lettres, Obituaires, série in- $8^{\circ}$, vol. 1), p. 463-464 ; Berlière (U.), Abbaye de Saint-Laurent à Liège, MONASTICON BELGE, t. II, Province de Liège, 1928, p. 54-55 et IDEM, Abbaye Saint-Jacques à Liège, IBIDEM, p. 11-12 et 23; RESMINI (B), Die Benediktinerabtei Laach, Berlin-New York, 1993, p. 351-2 (GERMANIA SACRA, nv. série, t. XXI).

(19) Cf. Lemaitre, Mourir à Saint-Martial, op. cit., p. 360.

(20) Le formulaire des lettres, notamment de fraternité, de Wibald, est étudié par REUTER, Gedenküberliefenung, op. cit., p. 170. 
établir de nouvelles : Reims, Prüm, Cornelimünster, Saint-Michel-enThiérache, Cologne, Averbode. Nous ne pouvons nous empêcher de mettre ce zèle en parallèle avec celui qu'il déploya dans l'acquisition et la conservation de reliques pour son abbaye (21).

Nous avons établi un classement distinct des actes : deux concernent l'abbaye, six le seul monastère de Stavelot et cinq autres celui de Malmedy. Au sein de ces trois divisions, nous avons respecté l'ordre chronologique. Nous donnerons la référence dans HR et/ou l'édition la plus récente.

\section{A. Stavelot-Malmedy}

\section{Corvey, 1147 ? (HR 187)}

En 1147 (22), les moines de Corvey écrivent à leurs confrères de Stavelot pour établir une entraide spirituelle pendant la vie et la prière pour les morts : intimam dilectionem vere fraternitatis et devotissimum munus assidue orationis. Cette association ou communauté spirituelle est subtilement définie, introduite par trois références bibliques. A cette époque, Wibald est abbé de Corvey et de Stavelot-Malmedy; il a réglé les problèmes de Corvey et notamment récupéré cent manses aliénés ; les deux monastères sont unis sous sa crosse : c'est le moment de mettre sur pied une confraternité qui s'établira dans chaque établissement selon la coutume suivie - secundum nostram consuetudinem, secundum vestram consuetudinem (23). Avec une clause supplémentaire: si un

(21) Cf. notre article Erlebald († 1192), gardien des reliques de Stavelot-Malmedy, LE MOYEN AGE, t. XC, 1984, p. 375-382.

(22) Date suggérée par Wibaldi epistolae, éd. JAFFE ( $\mathrm{Ph}$.), BibliotheCA RERUM GERMANICARUM, t. I, MONUMENTA CORBEIENSIA, 1864, p. 76-622, n' 50 p. 127 (ci-dessous abrégé $J$ suivi du $\mathrm{n}^{\circ}$ de la lettre : $\mathrm{J}$ 50) repris par HR 187 . Wibald fut élu abbé de Corvey le 20 octobre 1146.

(23) Les moines connaissent bien leur coutume et jugent inutile de la détailler. La consuetudo de Corvey est expliquée par REUTER (Th.), Gedenküberlieferung und -praxis im Briefbuch Wibalds von Stablo, dans Der Liber Vitae der Abtei Convey. Studien zur Corveyer Gedenküberlieferung und zur Erschliessung des Liber Vitae, éd. SCHMID (K.) et WOLLASCH (J.), Wiesbaden, 1989 (Societas et Fraternitas, Bestandteil des Quellenwerkes, VEROFFENTLICHUNGEN DER HISTORISCHEN KOMMISSION FÜR WESTFALEN 40, WESTFÄLISCHE GEDENKBUCHER UND NEKROLOGIEN 2), p. 161-177, p. 164, à partir du cas de l'abbé Henri Irr déposé et accueilli dans plusieurs monastères. 
frère est exclus d'une des deux abbayes à cause de ses fautes - propter vitia - il sera accueilli materne dans l'autre jusqu'à la réconciliation.

Un acte postérieur (HR 188) conserve les noms des moines de la confraternité - in plena fraternitate et una eademque societate magno utrimque studio et pari voluntate - 44 pour Stavelot, y compris Wibald, et 27 pour Malmedy (24).

Dans ces liens étroits des deux établissements sous l'abbatiat de Wibald s'élabore la commémoration réciproque de leur saint patron (HR 200) : en 1151, Wibald fonde la fête de saint Remacle à Corvey (25); quant au culte de saint Vit, on ignore quand il fut introduit à Stavelot mais Wibald le développa (26). Quelques années plus tard, dans une lettre aux moines de Stavelot, Wibald leur rappelle la confraternité qui les unit désormais à Corvey (HR 226).

\section{Cornelimünster, 1174-1192 (HR 278)}

Le problème des moines transfuges retient précisément l'attention des abbés Florentius de Cornelimünster et Erlebald de Stavelot dans la disposition qu'ils ajoutent à l'ancienne confraternité entre les deux monastères, dont le règlement général n'est pas conservé. Si un frère est expulsé de sa maison, il pourra trouver asile dans l'autre, autant de temps qu'il le désirera («accueil, hébergement, nourriture et toute charité »).

Les abbés rappellent qu'au décès d'un moine, de part et d'autre, trente offices seront célébrés.

Les relations entre les deux monastères sont anciennes et attestées au IX ${ }^{\mathrm{e}}$ siècle déjà quand l'abbé Airic de Cornelimünster avait été l'inspirateur des Miracula Sancti Remacli (27).

(24) Cf. JAKOBI, op. cit., p. 263-265 et ReUTER, Gedenküberliefenung, op. cit., p. 163 Sv..

(25) ERHARd (H.A.), Regesta Historiae Westfaliae accedit Codex Diplomaticus 2 : 11261200, Münster, 1851 (Codex diplomaticus), p. 611 sv. n' CCLXXVIII, cité d'après ReUTER, Gedenküberlieferung, op. cit., p. 163 sv. et commentaires dans JAKOBI, op. cit., p. 264265 ; cf. aussi JAKOBI, op. cit., p. 247-248 et 258.

(26) GEORGE, Les reliques de Stavelot-Malmedy, op. cit., p. 133 ; le toponyme SaintVith est pour la première fois attesté en 1130-1131 (HR 153).

(27) Baix (Fr.), Saint Remacle. Culte \& reliques (I), FolkLore Stavelot- Malmedy, t. XVIII, 1954, p. 13. 
B. Stavelot

3. Solignac, 1134 (HR 158), renouvelée en 1238 (HR 320 (28)).

La figure de saint Remacle, abbé de Solignac et fondateur de Stavelot-Malmedy, domine les relations entre les deux établissements (29).

Renouvelée en 1238, la confraternité l'avait déjà été en 1134 lors d'une visite à Solignac de Wibald et de deux moines de Stavelot. Au chapitre en commun, après un sermon sur la charité, les deux abbés, Maurice de Solignac et Wibald de Stavelot, avaient réaffirmé les liens des deux établissements dans le souvenir de saint Remacle : renovata et confirmata est societas atque fraternitas.

Même si les distances sont grandes entre les deux maisons, les frères ne font «qu'un seul cœur et qu'un seul esprit», ce qui se traduit par des prières pour les vivants comme pour les morts et une "prébende " pour tout moine qui séjournerait. Comme l'annonce du décès d'un moine peut mettre longtemps à parvenir d'un monastère à l'autre, chaque année on célébrera sept offices complets pour les défunts et sept messes seront chantées par des prêtres. Les noms des morts seront inscrits au nécrologe (martyrologio (30)) de Solignac. Pour le décès d'un abbé, chaque abbaye célèbrera, comme pour le sien, des obsèques et offices. On veillera à l'avenir à envoyer des messagers pour avertir des décès.

Wibald est commémoré dans l'obituaire de Solignac au 19 juillet et, au 4 novembre, on trouve la notice suivante : Conmemoratio fratrum defunctorum sancti Remacli Stabulensis (31).

Une correspondance entre les deux établissements est conservée ( $\mathrm{J}$ $175, \mathrm{~J} 176)$ : en 1149, Wibald remercie Guiraud, abbé de Solignac, des nouvelles reçues; il lui demande deux couples de lapins car il compte vraisemblablement se livrer à la cuniculiculture (32).

(28) Réédition dans LEMAîRE, Les documents nécrologiques de Solignac, op. cit., p. 7880,187 et $465-466$.

(29) BAIX (Fr.), Saint Remacle et les abbayes de Solignac et dé Stavelot-Malmedy, REvue BÉnédictine, t. LXI, 1951, p. 167-207. Cf. aussi Reuter, Gedenküberliefenung, op. cit., p. 164-165.

(30) Terme utilisé pour désigner le nécrologe, cf. Lemaître, Mourir à Saint-Martial, op. cit., p. 362.

(31) LeMAITRE, Les documents nécrologiques de Solignac, op. cit., p. 169 et 187.

(32) STIENNON (J.), Quelques aspects du bestiaire mosan au moyen âge dans la littérature, l'histoire et la miniature, ACAdémie royale de Belgioue, BUlletin de la Classe DES LeTtRes \& DES SCIENCES MORALES \& POLITIOUES, 5 série, t. LXXV, 1989, p. 265 sv.. 
Des reliques sont également échangées : en 1268, lors de l'envoi d'un bras de saint Remacle à Solignac, référence est faite à la confraternité (HR 348).

\section{Saint-Maur-des-Fossés, 1134 (HR 288)}

La plupart des associations de prières de l'abbaye des Fossés ont été transcrites à la suite de l'obituaire du XII ${ }^{e}$ siècle dont les fragments sont conservés aujourd'hui au Vatican (33).

Statuta est hec fraternitas sous les abbés Wibald et Ascelin. C'est peut-être lors d'un séjour de Wibald à Saint-Maur que cet acte est passé puisque, la même année, il séjourne à Solignac (34). Les dispositions de la fraternité sont réglées comme suit : pour les abbés défunts, de part et d'autre, on célèbrera un plenum tricenarium. Comme les distances sont grandes entre les deux monastères et que la nouvelle d'un décès pourrait ne pas parvenir, chaque année en novembre, chaque abbaye célèbrera trois offices pour les frères défunts au chapitre après avoir récité la commémoration des moines.

La Saint-Remacle est présente au calendrier liturgique des Fossés dès le XII ${ }^{e}$ siècle; elle est célébrée à huit leçons, ce qui est fort honorable (35). Saint Quirin (11 octobre) s'y trouve à partir du XIII ${ }^{e}$ siècle. I. J. de Jésus-Maria (36) signale parmi l'inventaire des reliques contenues dans un grand reliquaire de bois de l'église de Saint-Maur : "18. Du suaire de sainct Remolde", qui pourrait bien être saint Remacle.

Où cette confraternité trouve-t-elle son origine? Quels motifs ont poussé Wibald à conclure cette fraternité ?

La Vita Baboleni (BHL 886), ca. 1058-1067, utilise la Vita Remacli et confond Babolène de Stavelot avec le premier abbé homonyme des

(33) VAtican, Reg. lat. 566 et 863. Éd. par Prou (M.), Fragments d'un obituaire de Saint-Maur-des-Fossés, MémoIRes de LA Societé de L'HistoIre de PARIS \& DE L'ILe DE FrANCE, t. XIV, 1887, p. 209-238. L'acte de 1134 s'y trouve reproduit.

(34) Cf. supra.

(35) RENAUdin (A.), Le calendrier de Saint-Maur-des-Fossés, dans Deux antiphonaires de Saint-Maur, EtUdes GrÉgoriennes, t. XIII, 1972, p. 81-93. A Saint-Maur, saint Remacle est inscrit au missel du XIV ${ }^{e}$ siècle (PARIS, BibliothèQUE NATIONALE, Manuscrit lat. 12060, cf. LEROQUAIS (V.), Les sacramentaires et les missels manuscrits des bibliothèques publiques de France, 3 vol. et pl., Paris, 1924, t. II, p. 294, au bréviaire du XIII' siècle (Troyes, Bibliothéque municipale Manuscrit 1752, cf. Leroquais (V.), Les bréviaires manuscrits des bibliothèques publiques de France, 5 vol. et pl., Paris, 1934, t. IV, p. 239) et au diurnal du XIII ${ }^{e}$ siècle (PARIS, BIBLIOTHËQUe NATIONAIE Manuscrit lat. 12037, cf. LEROQUAIS, Bréviaires, op. cit., t. IV, p. 384).

(36) I.J. de Jesus-Maria, La Vie de S. Maur, Paris, 1640, p. 459. 
Fossés (37). Par ailleurs, on trouve des reliques de saint Maur dans l'autel de saint Benoît à Stavelot ainsi qu'une Vie du saint dans le catalogue de 1105 de la bibliothèque (38). S'agit-il du patron des Fossés ? Ermite angevin du VI e siècle, il passa, à l'époque carolingienne, avec succès pour le disciple homonyme de saint Benoît, qui aurait introduit la Règle bénédictine en Gaule. La châsse de saint Maur avait été ouverte aux Fossés en 1030.

Par ailleurs, au $\mathrm{XI}^{e}$ siècle, les moines de Stavelot envoyèrent un exemplaire du Livre II du Triumphus sancti Remacli à leurs confrères de Saint-Maur dans l'espoir qu'ils se joindraient à eux pour célébrer la fête du Triomphe de saint Remacle (9 mai) (39).

\section{Saint-Michel-en-Thiérache, 1169 (HR 262)}

En 1169, à la demande de l'abbé Guillaume, la fraternité est renouvelée entre Saint-Michel et Stavelot, sous l'abbatiat d'Erlebald : renovata est societas.

Les abbés auront droit à un trentain, les frères à un septain. Chaque année, «le jour après l'octave des Apôtres », le 7 juillet, de part et d'autre, se fera de manière solennelle la mémoire des morts, aux vigiles et à la messe.

Saint-Michel obtient le chevage des hommes appartenant à l'autel de saint Remacle, ceux qui habitent entre le château de Guise et Rumigny ; ces hommes de la familia de saint Remacle paieront le cens annuel à l'abbé ou au monastère de Saint-Michel et l'église de SaintMichel acquittera deux sous de Châlons à l'autel de saint Remacle chaque année à la Saint-Jean-Baptiste (40).

(37) Monsieur Pierre Gillon a grandement facilité notre information sur les sources fossétoises et nous l'en remercions vivement.

(38) Michiels (G.), La vie intellectuelle à l'abbaye de Stavelot durant le haut Moyen Age, Folklore Stavelot-Malmedy, t. XX-XXVII, 1956-1963, p. 5-24 et t. XXVIII, 1964 , p. $75-104$; ici en particulier p. 15.

(39) Le manuscrit est conservé au Vatican, Reg. 1316. Commentaires dans de GaifFIER (B.), L'hagiographie dans le Marquisat de Flandre et le Duché de Basse-Lotharingie au XI' siècle, ÉTUDES CRITIQUES D'HAGIOGRAPHIE \& D'ICONOLOGIE, Bruxelles, 1967, p. 501502 (Subsidia HagiograPHICA, $n^{\circ}$ XLIII).

(40) Misonne (D.), La charte de Raoul de Laon relative à l'établissement de moines scots à Saint-Michel-en-Thiérache (3 février 945), REVUE BÉNÉDICTINE, t. LXXIV, 1964, p. 298-307 et IDEM, Le moine Kaddroe et ses fondations de Saint-Michel-en-Thiérache, de Waulsort et de Saint-Clément de Metz, Au PAYS DES RIÈzES ET DES SARTS, t. XXII, 1981, $\mathrm{n}^{\circ}$ 85, p. 414-424. Cf. aussi BaIX (F.), Saint Remacle et les églises de Reims et de Trèves, FolkLORE STAVELOT-MALMEDY, t. XV, 1951, p. 15. 


\section{Prüm, 1187 (HR 274)}

En 1187, Stavelot et Prüm renouvellent par un écrit leur confraternité - fraternitatem.

Quand meurt un frère de Stavelot, ceux de Prüm célèbreront trente messes et vigiles en convent et au chapitre, accompagnées du psaume "Verba mea ». Si un frère accusé d'une faute est exilé de l'abbaye, il obtiendra aide et conseil - opem consilii et auxilii - dans l'autre monastère qui favorisera la réconciliation. L'acte est conclu sous l'abbatiat d'Erlebald de Stavelot et de Gérard de Prüm.

Dès le $\mathrm{IX}^{\mathrm{e}}$ siècle, le culte de saint Remacle est attesté à Prüm, ainsi que plus tard le culte d'autres saints stavelotains (41). Une relique de saint Remacle est à Prüm dès 1003 (42).

\section{Reims, Saint-Remi, 1151-1162}

L'obituaire de Saint-Remi de Reims révèle les clauses de la confraternité entre l'abbaye rémoise et Stavelot, conclue sous l'abbatiat d'Hugues de Saint-Remi (1151-1162) (43).

(41) HAubrichs (W.), Die Kultur der Abtei Prüm zur Karolingerzeit. Studien zur Heimat des althochdeutschen Georgsliedes, Bonn, 1979, e. a. p. 153 et 177 (RHEINISCHES ARCHIV, t. CV). Par contre, aucune mention de liens avec Stavelot dans AlTHOFF (G.), Eine Prümer Mönchsliste im "Liber Aureus», FrÜHMITTELALTERLICHE STUDIEN, t. VII, 1973, p. 234265, ni dans Annales necrologici Prumienses, MGH, SS, t. XIII, 1881, p. 219-223. Un martyrologe du XIII siècle (BONN, BIBLIOTHÉQUE DE L'UNIVERSITE, Manuscrit 370 (226, v.b.)) et un missel du XIV ${ }^{e}$ siècle portent témoignage de la célébration à Prüm de la fête de saint Remacle, dont une Vie était encore conservée au XVIII ${ }^{e}$ siècle dans la bibliothèque de l'abbaye, ainsi que l'ont signalé Martène et Durand (Cf. Mresges (P.), Der Trierer Festkalender. Seine Entwicklung und seine Verwendung zu Urkundendatienungen. Ein Beitrag zur Heortologie und Chronologie des Mittelalters, Trèves, 1915, p. 16 et 82).

Saint Remacle n'est pas commémoré dans le martyrologe métrique de Wandelbert de Prüm (cf. DuBors (J.), Le martyrologe métrique de Wandelbert. Ses sources. Son originalité. Son influence sur le martyrologe d'Usuard, ANALECTA BOLlandiANA, t. LXXIX, 1961, p. 257-293 et 510). Le manuscrit de Madrid (BIBliothèQue NATIONALE 3307) conserve un calendrier de Prüm du IX siècle, sur lequel la fête de saint Remacle a été ajoutée au 3 septembre (Cf. Boschen (L.), Die Annales Prumienses. Ihre nähere und ihre weitere Venwandtschaft, Düsseldorf, 1972, p. 49).

(42) BaiX, Saint Remacle. Culte \& Reliques (II), Folklore Stavelot-Malmedy, t. XIX, 1955, p. 15 et IDEM, Reims et Trèves, op. cit., p. 27.

(43) Reims, Bibliothéqu municipale, Manuscrit $346, \mathrm{f}^{\circ} 190$; cf. Falkenstein (L.), Aquensia aus der Champagne, ZEITSCHRIFT DES AACHENER GESCHICHTSVEREINS, t. 84/85, 1977/78, t. II, Aachen, 1978, Freudesgabe FUr B. POl, p. 418 et IDEM, Berensberg, p. 8-9. Cf. aussi REUTER, Gedenküberlieferung, op. cit., p. 165. Sur cet obituaire, cf. Lemaître, Répentoire, op. cit., nº 1699. 
Heç est societas inter ecclesiam sancti Remacli, quod scil(icet) pro abbatibus ab vita decedentibus in alterutra ecclesia tricenarius persolvatur, pro reliquis vero fratribus, cum fuerit eius auditus obitus, generale officium et missa in conventu celebrabitur. Insuper etiam ab unoquoque sacerdote I missa cantabitur et ab aliis fratribus $L$ psalmi et post festivitatem sancti Luce evangeliste generale officium cum tricenario et prebenda.

Pour le décès d'un abbé, un trentain; pour un frère, à l'annonce de son décès, un office général et une messe en convent. En plus, une messe sera chantée par chaque prêtre et cinquante psaumes par les autres frères. Après la Saint-Luc (18 octobre) un office général avec trentain et prébende.

En 1160, Erlebald de Stavelot cède à Hugues de Saint-Remi la villa de Germigny avec ses dépendances (44), moyennant le paiement annuel dc huit marcs d'argent à la fête de saint Jean-Baptiste (HR 252). Ludwig Falkenstein suppose, avec beaucoup de vraisemblance, que cette transaction est à l'origine de l'association de prières entre les deux abbayes. Déjà en 1148, Odon, abbé de Saint-Remi, notifiait dans une lettre à Wibald et aux moines de Stavelot la mort du frère Etienne survenue le 14 octobre (HR 212). D'autres relations entre Stavelot et Saint-Remi sont attestées (HR 270-271).

Dans le même obituaire, une addition répertorie les différents établissements unis par confraternité (45): Pro mo(nachis) sancti Remacli in festo sancti Luce tricenarius, abbatibus quoque tricenarius. Cette note, inscrite dans le cadre du propre des saints sous l'abbatiat d'Hugues de Saint-Remi (1151-1162), rappelle la confraternité qui est fixée à la Saint-Luc.

La fête de saint Remacle est inscrite au calendrier du monastère (46). De nombreuses reliques de saint Remi sont présentes à Stavelot et à Malmedy. Une activité autour des reliques de saint Remi est attestée à Reims vers 1049 quand le pape Léon IX vient en personne consacrer la nouvelle abbatiale dédiée au saint évêque (47). C'est

(44) Sur Germigny, cf. Gallia monastica. Tome I : Les abbayes bénédictines du diocèse de Reims, par Poirier-Coutansars (Fr.), Paris, 1974, p. 68.

(45) Au folio 191 verso. Au moins 121 établissements, cf. FaLKenstein, op. cit., p. 409 n. 60 et FALKenstern (L.), Le calendrier des commémorations fixes pour les communautés associées à l'abbaye de Saint-Remi au cours du XII siècle, L'ÉGLISE \& LA MÉMOIRE DES Morts dans la France mediévale. Communications présentées à la Table ronde du C.N.R.S., le 14 juin 1982, réunies par Lemaitre (J.-L.), Paris, 1986, p. 23-29.

(46) BaIX, Reims et Trèves, op. cit., p. 15-16.

(47) Cf. Ravaux (J.-P.), L'église Saint-Remi de Reims au XIe siècle, Bulletin ARCHEOLOGIQUE DU COMITE DES TRAVAUX HISTORIQUES ET SCIENTIFIQUES, nv. série, t. VIII, 1972, Paris, 1975, p. 51. 
d'ailleurs lors de ce séjour à Reims que le pape accorde deux privilèges en faveur de Stavelot (HR 110 et 112). On notera la présence de reliques de saint Remi dans l'autel Saint-Martin à Stavelot, dont la dédicace n'est pas datée. Toutefois, dès 1030 au moins, Stavelot a des reliques de Remi.

Remi est invoqué dans les litanies de Stavelot aux $\mathrm{X}^{\mathrm{e}}, \mathrm{XI}^{\mathrm{e}}$ et $\mathrm{XII}^{\mathrm{e}}$ siècles (48). Des textes hagiographiques lui sont consacrés dans un manuscrit du Xe siècle (?) provenant de Stavelot (49), sans compter que sa fête sert naturellement de repère dans l'année (HR 144 et 282) (50).

\section{Saint-Hubert, 1211 (HR 295)}

En 1211, Adélard, abbé de Stavelot et ses moines concluent avec l'abbé Guillaume de Saint-Hubert et son monastère une confraternité. Hec forma placuit fraternitatis.

Pour la mort d'un abbé, un office sera célébré comme pour l'abbé du lieu et son nom sera inscrit in regula. Les noms des frères seront transmis par messagers ; un service d'obsèques sera organisé, et un trentain pour chacun avec inscription du nom in regula. Si un frère veut aller dans l'autre monastère, avec une lettre de l'abbé, il y sera accueilli comme un fils. S'il est exilé pour ses fautes, de même il sera accepté jusqu'à ce qu'il obtienne le pardon. La lettre se termine par des propos généraux sur les liens établis, avec une réminiscence littéraire de Salluste (51).

\section{MALMedy}

9. Averbode, 1173 (HR 265)

En 1166, Henri l'Aveugle, comte de Namur et avoué de StavelotMalmedy, rend au monastère de Malmedy la terre de Roclenge qu'il

(48) Coens (M.), Litanies de Stavelot, RecueIl d'Etudes bollandiennes, Bruxelles, 1963, p. 228, 238 et 240 (Subsidia Hagiographica, n 37).

(49) Bruxelles, Bibliotheque royale, Manuscrit II 2568 fol. 88-147v; cf. MichIELS, op. cit., p. 94.

(50) Une fontaine Saint-Remi est attestée aux environs de Malmedy à Faymonville, sans que l'on connaisse l'origine du toponyme, cf. BASTIN (J.), Notice historique sur la commune de Faymonville, FolkLORE STAVELOT-MALMEDY, t. III, 1924, p. 139.

(51) SALluSTE, Catilina, 20, d'après HR 295.

Les fragments d'obituaire publiés par Godefroid Kurth ici-même (BULLETIN DE LA COMMISsion Royale D'Histoire, 5e série, t. VIII, p. 92-105) n'apportent rien sur Stavelot-Malmedy; rien non plus dans KURTH (G.), Chartes de l'abbaye de Saint-Hubert en Ardenne, Bruxelles, 1903. 
tenait en fief dudit monastère (52). Par deux actes, en 1166 et 1173, l'abbé Erlebald convertit ce fief en alleu qu'il donne à l'abbaye d'Averbode à deux conditions : la première est de célébrer deux anniversaires, et la seconde de payer à Malmedy, le 29 juin, un denier d'or de monnaie publique, changé dans le dernier acte en cinq sous de monnaie liégeoise. Les deux anniversaires furent fondés : le nécrologe d'Averbode commémore Wibald au 18 juillet (Ecriture du fonds primitif, 12471248) et l'ensemble de la communauté de Malmedy au 28 février (Ecriture du XIVe siècle) (53).

Le document de 1173 ne donne pas beaucoup de renseignements sur la societas conclue : Preterea silendum non est quia ecclesia nostra ecclesiam illam tamquam sororem in corporali et spirituali societate suscepit, filiisque illius universa beneficia sua communicavit, illa quoque econverso in memoriale dilectionis similia nobis rependens, abbatum et fratrum ecclesie nostre anniversarium nichilominus quam suorum ibidem sollempniter celebrabit. Hec igitur tam libere a nobis facta, ut rata in perpetuum et inconvulsa permaneant, ad posteronum noticiam scripto transmittere curavimus (54).

\section{Cologne, Notre-Dame-aux-Degrés, 1179 (HR 269 et 307)}

En 1179, le prévôt Hugues et le doyen Gérard de l'église NotreDame-aux-Degrés de Cologne renouvellent la fraternité entre leur église et celle de Malmedy : fraternitatis unionem (...) hanc societatem.

Outre la dépendance diocésaine de Malmedy à Cologne, les deux églises sont liées par le culte de saint Agilolf; le corps de ce pseudo-

(52) de NOUE (A.), Rockelingen sive Ruckelingen en français Roclenge, Province de Limbourg. Trois diplômes du XIIr siècle, BULLETIN DE L'INSTITUT ARCHEOLOGIQUE LIEGEOIS, t. VII, 1865, p. 107-122. Il s'agit de Roclenge-Looz (Rukkelingen-Loon) et non de Roclenge-sur-Geer (VERCAUTEREN (F.), Un clerc liégeois du XII siècle : maitre Benoft de Saint-Jean, LE MOYEN AGE, t. LXXIII, 1967, p. 46-47).

(53) Necrologium Monasterii S. Mariae Sanctique Joannis Baptistae in Averbode $O$. P., éd. SLECHTEN (E. H. G. ), Averbode, s. d., p. 85 et 207.

(54) Averbode est unie en confraternité avec Munsterbilzen (début du XIII siècle), Saint-Barthélemy de Liège $(1236,1297)$, les Cisterciens de Notre-Dame de Ruremonde (1292), le béguinage d'Aarschot (1294), l'abbaye Saint-Nicolas de Reims (1296), le prieuré de Bierbeek (1296), les chanoines de Looz (1296), le Val des Écoliers à Liège (1297) et les Cisterciennes d'Orientem (1301). Sous l'abbatiat d'André (c. 1139-1166) fut conclue une fraternité avec l'Ordre de Cîteaux en présence de saint Bernard. D'après KoyEN (M.), Abbaye d'Averbode, Monasticon Belge, t. IV, Province de Brabant, 1969, p. 629, 632, 636 et 642 . 
abbé de Malmedy fut transféré à Cologne à Notre-Dame-aux-Degrés le 9 juillet 1062 par l'archevêque Annon (55).

Le document n'entre pas dans le détail pratique de la fraternité : Notum sit nos eos in orationum ecclesiae nostrae suffragio et eleemosynarum nostrarum beneficio, officio et auxilio nunc et perenniter suscepisse et nos viceversa suis orationibus, beneficiis et eleemosynis tam vivos quam defunctos fideliter communisse. L'acte est conclu sous l'abbatiat d'Erlebald de Stavelot. Vers 1220, les religieux de Malmedy rappellent l'existence de ce traité à leurs confrères de Cologne : confraternitas inter ecclesiam vestram et nostram. "Souvenez-vous de nous dans vos prières, et vice-versa » (56).

\section{Saint-Hubert, 1212 (HR 297)}

Après avoir renouvelé en 1211 avec ses moines de Stavelot le traité de confraternité avec Saint-Hubert, c'est cette fois avec ceux de Malmedy que l'abbé Adélard souscrit un an plus tard un même acte. Le dispositif de la charte est en tous points semblable à celui de la charte de Stavelot.

\section{Trèves, Cathédrale, 1218 (HR 303)}

En 1218, l'abbé Alard, au nom des religieux de Malmedy, informe le chapitre cathédral de Trèves qu'il a pourvu le chantre Conon de la cure de Clotten (57). S'ensuivent des dispositions de fraternité : Communionem insuper omnium bonorum que apud nos fient vobis concedimus, statuentes ut obitus defunctorum vestrorum quemadmodum et nostrorum apud nos celebrentur, et a nostro refectorio, cum presentes fuerint ex vestris fratribus aliqui, refectionem percipiant eandem quam et fratres nostri, ut sicut in vita unum sumus, sic etiam in morte non accidat separari.

(55) Stiennon (J.), Le rôle d'Annon de Cologne et de Godefroid le Barbu dans la rédaction de la Passio Agilolfi (1060-1062), Le MOYEN AGE, t. LXV, 1959, p. 225-244.

(56) Le nécrologe de la seconde moitié du XIII' siècle (Totenbuch St. Maria ad gradus, éd. LACOMBlet (Th. J.), ARChIV Fúr DEN GESCHICHTE des NIEDERRHEINS, t. II, 1857, p. 49-56) ne porte aucune commémoration de moines malmédiens, ni stavelotains.

(57) VAN REY (M.), Der deutsche Fermbesitz der Klöster und Stifte der alten Diözese Lüttich, vornehmlich an Rhein, Mosel, Ahr und in Rheinhessen, ANNALEN DES HISTORISCHEN VEREINS FUr NIEDERRHEIN, t. CLXXXVI, 1983, p. 19-80 et t. CLXXXVII, 1984, p. $31-89$; sur Clotten, p. $46-47$. 
La cathédrale de Trèves conserve un fragment de la chasuble de saint Remacle (58).

\section{UNE LISTE DES CONFRATERNITES DE STAVELOT COPIÉE AU XIVE SIËCLE}

Une liste énumérative des églises avec lesquelles le monastère de Stavelot était uni par confraternité a été copiée au XIVe siècle. Seul le titre et le lieu de l'église sont donnés; aucun détail sur les règles de confraternité. Il s'agit d'un répertoire sans ordre apparent immédiat.

Cette liste a pris place dans la célèbre Bible de Stavelot, conservée aujourd'hui à la British Library à Londres (59) et fut éditée par Halkin \& Roland (HR 1700); leurs références doivent être actualisées et nous rééditons le document en annexe 1.

56 établissements y sont répertoriés. Halkin \& Roland ne donnent aucune identification, ni aucun commentaire. Deux établissements supplémentaires - Houffalize et Bernardfagne - inscrits en bas de liste, ne figurent que dans la copie $E$ où ils sont introduits par la phrase : Quibus addi debent.

Six établissements - Malmedy, Solignac, Saint-Hubert, Cornelimünster, Prüm et Saint-Remi de Reims -, sont déjà connus par les actes de fraternité ; par contre y manquent quatre autres établissements cités précédemment: Saint-Maur-des-Fossés, Saint-Michel-en-Thiérache, Corvey et la cathédrale de Trèves, pourtant attestée par l'acte de confraternité le plus récent (1218). Aucune mention non plus de Remiremont, ni de Caen.

Les deux églises ajoutées en fin de liste dans la copie $E$ sont des fondations du XIII ${ }^{e}$ siècle, mais il est mentionné que $E$ copie $B$ et sa rédaction au XVI ${ }^{c}$ siècle nous empêche toute autre considération.

Les éditeurs Halkin \& Roland considèrent la transcription du XIV ${ }^{e}$ siècle $(B)$ comme l'original et l'appellent $A$. Il est bien sûr difficile de trancher au vu de ces seuls documents. Toutefois quelques commentaires s'imposent.

Toutes les copies émanent de $B$; cela apparaît clairement dans $D$ et $E$ : extractus ex antiquissimo libro pergamenico in maxima forma biblio-

(58) GeORGE, Les reliques de Stavelot-Malmedy, op. cit., p. 33-34.

(59) A titre de comparaison, à Saint-Martial de Limoges, on trouve la copie du XIc siècle d'un acte de confraternité de 942 sur le feuillet blanc de la première bible de l'abbaye (Lemaître, Mourir, op. cit., p. 365). 
thecae Stabulensis continente secundam partem bibliae sacrae folio penultimo verso. Quant à $C$, elle suit strictement l'ordre de $B$, ce qui nous fait penser qu'il s'agit d'une copie directe. Sur $C$, on trouve en outre, d'une écriture plus récente, quelques informations complémentaires : Quae sint loca precipua ad que pro tempore mittenda forent brevia pro fratre defuncto; nous les publions en annexe 4.

On notera tout d'abord la forte présence bénédictine : 46 établissements ; le reste est fait d'un monastère cistercien (60), de quatre chapitres de chanoines réguliers, et de cinq de chanoines séculiers.

Peut-on dater la liste ?

La mention du chapitre de Saint-Hadelin à Celles et non à Visé, où il s'installera dès 1338 , nous permet d'avancer la date de 1338 comme terminus ad quem. L'établissement le plus récent mentionné est le ValSaint-Lambert, fondé en 1202. On a vu que l'on ne trouvait pas de mention de la confraternité de 1218 de Trèves et que les deux établissements ajoutés en fin de liste sont des fondations du XIII ${ }^{e}$ siècle. Nous proposons la fourchette chronologique suivante : [1202-1218] - 1338.

Un ordre quelconque préside-t-il dans l'énumération des confraternités sur cette liste ? Il est difficile de répondre à cette question. On fera toutefois observer que les premiers établissements cités sont Malmedy, le monastère jumeau de Stavelot, Solignac et Saint-Eloi de Noyon liés au souvenir de Remacle le fondateur, Corvey l'autre monastère frère sous l'abbatiat de Wibald, et enfin Saint-Lambert de Liège, l'église-mère du diocèse.

Dans l'énumération on notera l'absence de Brauweiler (61), tout comme celle de Gladbach (62) : Poppon est pourtant inscrit au nécrologe de cette dernière abbaye (63); on conserve également une lettre de Wibald à Gladbach qui glorifie leur saint commun, saint Vit (64).

(60) A propos de La Sauve-Majeure, Jean-Loup Lemaître fait observer que la présence d'une seule abbaye cistercienne n'est pas surprenante, les Cisterciens s'étant opposés au développement des offices des morts dans leurs communautés (LEMATTRE, La SauveMajeure, op. cit., p. 10).

(61) Brauweiler (R.F.A., Rhénanie-Westphalie). Rien non plus dans WISPLINGHOFF (E.), Die Benediktinerabtei Brauweiler, Berlin-New York, 1992 (Germania SACRA, herausgegeben vom Max-Planck-Institut, nv. série, t. XXIX, Die Bistümer der Kirchenprovinz Köln, Das Erzbistum Köln, 5).

(62) Gladbach (R.F.A., Rhénanie-Westphalie).

(63) 25 janvier, BOHMER, Fontes, III, p. 358.

(64) REUTER, Gedenküberliefenung, op. cit., p. 168-169; sur le culte de ce saint à Gladbach, cf. BAYER (Cl.), Der verschollene Vitus-Schrein des Gladbacher Münsters : Inschriften und Ikonograhie, ANNALEN DEs HISTORISCHEN VEREINS Für NIEDERRHEIN, t. CVC, 1992, p. 68-99. 
La cartographie et l'examen du réseau tissé ne détermine pas une concentration particulière sur une aire géographique précise, sauf bien sûr en pays mosan ; ce sont avant tout les liens traditionnels entre établissements qui s'en dégagent.

Nous avons pu constater que les liens établis entre établissements permettent l'échange de cultes de saints et de reliques, et vice-versa. En ce qui concerne uniquement les reliques, nous trouvons des échanges avec divers établissements de Cologne, de Liège, de Metz ou de Trèves, avec Broqueroie, Celles, Florennes, Hautmont, Helmarshausen, Lobbes, Malmedy, Prüm, Reims, Saint-Amand, Saint-Hubert, Saint-Maur, Saint-Trond, Waulsort, et... Solignac. Nous revenons ainsi à la case-départ : le cas de Solignac avait en effet motivé notre enquête sur la circulation et l'échange de reliques à travers le réseau de fraternités. Notre hypothèse première se trouve étayée ; elle nous a conduit à une recherche bien plus ample qui récolta tant d'autres éléments intéressants : relations artistiques (Lobbes, Echternach...), économiques (Beaufays, Dinant, Val, Solignac...) ou religieuses sur le plan des réformes monastiques (Gorze, Saint-Trond).

Pour la facilité du lecteur, nous avons organisé le commentaire de la liste selon l'ordre alphabétique des noms des établissements, avec suivant entre crochets son ordre sur la liste [1 à 58].

\section{AbDinghof, voir Paderborn}

\section{AfFligem [54] (65)}

La liste des confraternités de l'abbaye d'Affligem, rédigée vers 1310 , en recense 22 mais aucune avec Stavelot.

Stavelot n'est pas non plus repris parmi les 62 établissements religieux en fraternité avec Affligem (66).

(65) Un des rares lieux sans mention du titulaire de l'église.

(66) COPPENS (C.), Liber anniversarium [Affligemensis] (1426-1427). Fontes Affligemenses, vol. 1, Hekelgem, 1966, p. 31 sv..

Cf. aussi DeSPY (G.), Les bénédictins en Brabant au XII siècle : la chronique de l'abbaye d'Afflighem, Problèmes d'Historre du Christianisme, t. XII, 1983, p. 51-116. On notera en plus les confraternités avec l'abbaye hollandaise de Rijnsburg (1239), avec Gembloux (ca. 1250), avec les abbayes bavaroises de Niederaltaich et Kremsmünster (ca. 12661300), avec les bénédictines de Hunnegem (1631) et avec Ninove (1681). D'après Despy-Meyer (A.) \& Gérard (Ch.), Abbaye d'Affligem, Monasticon Belge, t. IV, Province de Brabant, vol. 1, 1964, p. 35, 37, 40, 69 et 73. 
2. ANDENNE, Sainte-Begge [22]

On ne trouve pourtant aucune mention de liens entre Andenne et Stavelot (67) ; aucune trace non plus d'un culte significatif de saint Remacle à Andenne, ni de sainte Begge à Stavelot (68); aucun moine n'est commémoré dans l'Obituaire du Chapitre d'Andenne "remis au net l'an $1729 »(69)$.

ARRAS, voir VERDUN

3. BEAUfaYs, Sainte-Marie [55]

S. Marie Bellifageti : le toponyme Bellum Fagetum est attesté dans les sources vers 1215. En septembre 1215, Robert, évêque de Verdun, fait donation au prieuré d'une forêt dite Bellum Fagetum et le toponyme viendra supplanter le nom initial de Belle-Fontaine à une époque inconnue (70).

Beaufays est une abbaye double jusqu'en 1230-1238, date de l'établissement des religieuses à Vivegnis. Le 25 juin 1241, Frédéric, abbé de Stavelot et son convent, voulant participer aux mérites et aux prières des frères et des sœurs de Beaufays, leur donnent en compensation la

(67) Misson (P.), Le chapitre noble d'Andenne, 1889; Cartulaire de la commune d'Andenne, éd. LAHAYE (L.), 2 tomes, 1895-1896 ; RousSEAU (F.), Le monastère mérovingien d'Andenne, ANNALES DE la Societe aRChélogiQUe DE NAMUR, t. LIII, 1965, p. 35-59 et réimpr. anast. dans $A$ travers l'Histoire du Namurois, Bruxelles, 1977, p. 279304 (Crédit Communal, Collection Histoire in- $8^{\circ}, \mathrm{n}^{\circ}$ 46) ; DeSPY (G.), Etude critique sur un diplôme de l'empereur Henri $N$ pour l'abbaye d'Andenne (1erjuin 1101), LE MOYEN AGE, t. LVI, 1950, p. 221-245, et Note complémentaire, IBIDEM, 1954, p. 39-50.

(68) Une Vita $S$. Begge est répertoriée dans l'inventaire de 1105 de la bibliothèque de Stavelot (Michiels, op. cit., p. 15) et d'autre part saint Remacle est inscrit au sanctoral de deux missels d'Andenne du XIII' siècle (NAMur, Musée Diocésain, ${ }^{\circ}{ }^{\circ}$ 2, f. $282^{\nu}{ }^{*} 283^{r}$ et $\mathrm{n}^{\circ} 3$, f. 253-254r, cf. FAIDER (P.), Catalogue des manuscrits consenvés à Namur, Gembloux, 1934, p. 400-402).

(69) ANALECTES POUR SERVir A l'Histoire ecclesiastioue de BelgiQue, t. XV, 1878, p. 347- 368.

(70) Desmedt-Williot (G.), Prieuré de Beaufays, Monasticon belge, t. II Province de Liège, 1955, p. 347 et 350. 
dîme d'Andoumont (HR 326). Cette dîme fera l'objet d'un relief tout au long du Moyen Age (71).

\section{BeRnARDFAGNE, Sainte-Marie [58]}

En 1159, l'abbé Erlebald de Stavelot autorise la fondation à My de l'ermitage de Bernardfagne qui devint, en 1248, un monastère de Guillemites, aujourd'hui Petit Séminaire de Saint-Roch à Ferrières (72). En 1659 une confraternité existe entre Bernardfagne et Houffalize (73).

\section{BROGNE, Saint-Eugène [20]}

On ne trouve aucune mention de Stavelot parmi les confraternités de Brogne (74).

L'obituaire du XIII ${ }^{e}$ siècle porte mention au 29 avril de Bonifacius, sacerdos et monachus sancti Petri sanctique Remacli in Stabulau (75).

Aucune mention non plus de reliques de saint Remacle à Brogne (76).

(71) Archives de l'État a Liège, Fonds de Stavelot-Malmedy, II, 44 ; PONCElet (Ed.), Chartes du monastère de Beaufays-lez-Liège, Bulletin DE LA COMMISSION ROYALE D'Histolre, t. CIII, 1938, p. 30 et STEKKe (J.), Le monastère et l'église de Beaufays-lezLiège, Bulletin DE LA SOCIETE D'ART \& D'HisTOIRE du DiOCÉSE DE LIËGE, t. XXXVIII, 1953 , p. 1-69.

(72) HR 250 où la charte de fondation est reconstituée p. 84, n. 1.

(73) Poncelet (Ed.), Le monastère de Bernardfagne dit de Saint-Roch, BuLLETIN DE LA Société d'ART \& D'Histoire du Diocèse de Liège, t. XIII, 1902, p. 274- 275.

(74) Les confraternités ont fait l'objet d'une étude de Baix (Fr.) dans le DictionNAIRE D'Histoire \& DE GEOGRAPHIE ECClEsiastiQues, t. X, 1937, col. 826-828. Brogne était ainsi unie à La Thure (Solre-sur-Sambre), Saint-Pierre de Gand, Saint-Ghislain, Lobbes (1215), Gembloux (XII ${ }^{\mathrm{c}}$ siècle), Saint-Vincent de Metz, Saint-Jean de Valenciennes, Saint-Michel-en-Thiérache, Waulsort-Hastière, Florennes, Saint-Jacques et SaintLaurent à Liège, Malonne (vers 1200), Moulins (1587), Saint-Lambert de Liège (1446), Notre-Dame à Dinant et les Augustins de Bouvignes $(1621,1720)$. Bibliographie dans MisonNe (D.), La restauration monastique de Gérard de Brogne, ACTES DU COLloouE DU C.E.R.C.O.R., Naissance et fonctionnement des réseaux monastiques et canoniaux, SaintEticnne, 1991, p. 117-123.

(75) BARbier (J.), Obituaire de l'abbaye de Brogne, ANALECTES POUR SERVIr À L'HISTOIRE ECCLÉSIASTIQUE DE LA BELGIQUe, t. XVIII, 1882, p. 316.

(76) RAYSSIUS, (cf. infra note 79) p. 124-127 et ANALECTES, op. cit., t. XVIII, p. 345. Cf. aussi Misonne (D.), Gérard de Brogne et sa dévotion aux reliques, SACRIS ERUDIRI, t. XXV, 1982, p. 1-26. 


\section{BROQUEROIE, Saint-Denis [42]}

Aucune mention à Broqueroie (77).

Le martyrologe de l'abbaye mentionne saint Remacle au 3 septembre : Et natale sancti Remacli episcopi et confessoris ; l'obituaire qui suit ne commémore aucun moine de Stavelot ou même de Malmedy (78). En 1628, Arnold de Raysse ne mentionne aucune relique stavelotaine à Broqueroie (79); par contre, Philippe Brasseur (80): [Petrus antistes] contulit os unum Stabuleto, illudque remisit Sancti Popponis os speciale sui. Nec minus huic optans per dona sacrata favere coenobio, os itidem nuper (Anno 1640) habere dedit (81).

\section{BuRTSCHEID (82), Saint-Jean-Baptiste [23]}

Aucune commémoration de moines de Stavelot (ni de Malmedy) dans l'obituaire de Burtscheid du XVe siècle (83).

(77) D'après le Liber capituli, $\mathbf{f}^{\circ} 37 \mathrm{v}$ - 39v, Broqueroie est unie à Saint-Ghislain (1321) et à Crespin (1353). Le Liber capituli de Saint-Ghislain conservé à Mons (FAIDER (P.), Catalogue des manuscrits de Mons, 1934, no 358 p. 117) garde mention réciproque de la confraternité de Saint-Ghislain avec Broqueroie en 1321. On notera sans étonnement au passage que le martyrologe commémore saint Remacle (FAIDER, $n^{\circ} 353$, f. 40r) alors qu'aucune confraternité avec Stavelot-Malmedy n'est attestée.

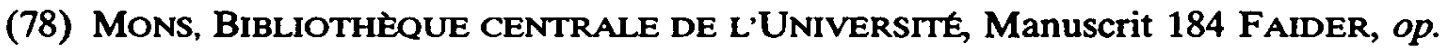
cit., $\mathrm{n}^{\circ}$ 553-557, p. 234-235.

(79) RAYSSIUS (A.), Hierogazophylacium Belgicum sive thesaunus sacranum reliquiarum Belgii, Douai, 1628.

(80) BRASSEUR (Ph.), Dionysiani monasterii sacrarium seu [...], Mons, 1641, p. 62.

(81) Ce témoignage est à ajouter aux recherches de W. LEGRAND sur le culte de saint Poppon (Chronique Archélologique du Pays de LiĖge, 1943, p. 25). On ne trouve pourtant aucune mention de reliquaire (Cf. Catalogue de l'exposition Trésors d'art de SaintDenis-en-Broqueroie, Mons, 1968), ni d'autres relations avec Stavelot-Malmedy. Les sources principales ont été dépouillées par Michel Revelard, auteur de recherches sur cette abbaye, qui nous a confirmé n'avoir jamais rencontré de liens entre les deux monastères (Revelard (M.), Les origines de l'abbaye de Saint-Denis-en-Broqueroie, AnNales du

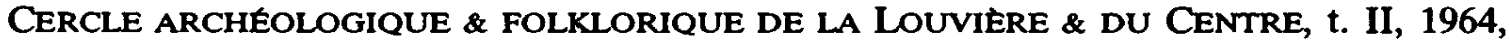
p. 45-54 et récemment PLISNIER (R.), Jean Mabillon et Saint-Denis-en-Broqueroie. À propos de deux livres conservés à la Bibliothèque de l'Université de Mons-Hainaut, ANNALES DU CERCLE ARChEOLOGIQUE DE MONS, t. LXXVI, 1994, p. 423-430).

(82) Nous avons préféré la forme allemande Burtscheid à la forme française Borcette, peu utilisée.

(83) BOSBACH (F. X.), Das älteste Burtscheider Nekrologium, ZeITSCHRIFT DES AACHENER GeschichtsvereINs, t. XX, Aachen, 1898, p. 90-178. Burtscheid était unie en fraternité à Saint-Jacques de Liège en 1377, cf. QuIX (Ch.), Geschichte der ehemaligen Reichsabtei Burtscheid, Aachen, 1834, p. 389-390. 
La Saint-Remacle est absente du calendrier établi en marge de cet obituaire. L'abbé Benoît de Burtscheid aurait été présent à la consécration de la nouvelle abbatiale de Stavelot le 5 juin 1040 (84).

\section{Celles, Saint-Hadelin [13]}

Hadelin, disciple de Remacle, avait fondé Celles-lez-Dinant. Nous avons insisté plus haut sur la localisation dans notre liste du chapitre de Saint-Hadelin à Celles, et non à Visé où ce chapitre ne s'installera qu'en 1338.

Des liens privilégiés existaient entre Stavelot et Celles. En la première moitié du $\mathrm{XI}^{\mathrm{e}}$ siècle, Hadelin, disciple de Remacle selon sa Vita, bénéficie de l'impact du culte de son maître. A Celles, la Saint-Remacle compte parmi les grandes fêtes liturgiques et Remacle est représenté sur la châsse mosane d'Hadelin des $\mathrm{XI}^{e}-\mathrm{XII}^{e}$ siècles. Des reliques de saint Hadelin sont par ailleurs présentes à Stavelot (85).

\section{Cologne, Saint-Martin [26]}

Aucune mention de moines de Stavelot-Malmedy dans le nécrologe de Saint-Martin de Cologne (86).

Curieuse mention en 1610 dans la châsse de saint Remacle de reliques de saint Eliphius dont les reliques sont conservées à Saint-Martin de Cologne (87).

En 1274, un doyen de Malmedy accompagne une délégation d'abbés colonais au concile de Lyon (88); c'est la seule mention, que nous

(84) Selon SchNock (H.), Studien über die Reihenfolge der Äbte und Äbtissinen in der ehemaligen Herrlichkeit Burtscheid, ZEITSCHRIFT DES AACHENER GESCHICHTSVEREINS, t. XLI, 1920, p. 210 ; cela nous paraît une pure hypothèse, car nous n'avons aucune mention du côté stavelotain et c'est pourtant un événement sur lequel nous sommes bien documentés.

(85) Cf. notre contribution Hadelin, saint mosan par excellence. Pour une histoire de son culte, Catalogue de l'exposition Trésors d'Art religieux au pays de Visé, éd. BRUYEREBoutier (P. \& M.-G.), Visé, 1988, p. 79-81, à laquelle on ajoutera BAIX (Fr.), Le souvenir de saint Remacle dans le Namurois, ÉTUDES D'HISTOIRE \& D'ARCHÉLOGIE NAMUROISES DEDIEEs A F. COURTOY, Gembloux, 1952, t. I, p. 173-184.

(86) Excerpta ex kalendario necrologico sancti Martini Maioris Coloniensis, publiés par Bömer (J.-F.), Fontes Rerum GeRMANICARUM, Stuttgart, t. III, 1853, p. 347- 348.

(87) OPLADEN (P.), Gross St-Martin. Geschichte einer stadtkölnischen Abtei, Düsseldorf, 1954, p. 109 sv. (STUdien ZUR KOLNER KIRCHENGESCHICHTE, t. II).

(88) IDEM, p. 33. 
ayons rencontrée dans les sources de contacts avec Malmedy (qui relève de Cologne) et non avec Stavelot.

\section{Cologne, Saint-Pantaléon [25]}

Aucune mention de confraternité du côté colonais (89); aucune mention de moines de Stavelot dans l'obituaire.

La fête de saint Remacle est au calendrier de Saint-Pantaléon de Cologne dans des manuscrits des $\mathrm{XIII}^{e}$ et $\mathrm{XIV}^{e}$ siècles (90), et la fête de saint Agilolf au 9 juillet.

Pantaléon est inscrit parmi les saints invoqués dans les litanies de Stavelot au XIe siècle (91).

Aucune mention non plus de reliques stavelotaines dans l'inventaire colonais du XIVc siècle (92).

Saint-Pantaléon fut touchée par la réforme de Gorze (93).

Parmi les reliques importantes du monastère, celles de saint Maurin et de saint Albin. Albine est dans les litanies de Stavelot au $X^{c}$ siècle (94). Le corps du saint fut ramené de Rome par l'impératrice Théophano (95).

\section{COMPIÈGNE, Saint-Corneille [51]}

Aucune mention de confraternité, ni de moines de Stavelot dans les nécrologes de Compiègne, ni de reliques (96).

(89) St-Pantaléon est unie avec Helmarshausen, Lubeck, Stade... L'étude des confraternités de Saint-Pantaléon reste à faire d'après les mentions du nécrologe, cf. Totenbuch St-Pantaleon, éd. Hilliger (B.), Publikationen der Gesellschaft fur Rheinische GESCHICHTSKUNDE, t. XX, Bonn, 1902, p. 1-85.

(90) ZiLLIKEN (G.), Der Kölner Festkalender. Seine Entwicklung und seine Venvendung zu Urkundendatierungen. Ein Beitrag zur Heortologie und Chronologie des Mittelalters, p. 28 et 94-95.

(91) COENS, op. cit., p. 237.

(92) Hilliger, op. cit., p. 2.

(93) KRACHT (H.-J.), Geschichte der Benediktinerabtei St.-Pantaleon in Köln 965-1250, Siegburg, 1975, p. 52 sv. (STUDIEN ZUR KOLNER KIRCHENGESCHICHTE, t. XI).

(94) COENS, op. cit., p. 237.

(95) Fried (J.), Kaiserin Theophanu und das Reich, Festschrift O. Engels, Vienne, 1993, p. 181 sv..

(96) Paris, Bibliothèue Nationale, Manuscrit Latin 17307 (Cf. Lemaftre, Répertoire, op. cit., $\mathrm{n}^{\circ}$ 1723). Les autres obituaires sont de l'époque moderne. Monsieur Philippe Racinet, auteur de la notice relative à l'abbaye dans Abbayes \& prieurés de l'ancienne France, sous la direction de Dom J. BECQUET, a vérifié pour nous sa documentation et n'a pas trouvé de relique de Remacle à l'abbaye. 


\section{CORBIE (CORVEY), Saint-Pierre [4]}

Sans doute la « Nouvelle Corbie », c'est-à-dire Corvey en Saxe dont les liens avec Stavelot furent étroits sous l'abbatiat de Wibald. Corvey avait été fondée par Corbie (97); Wibald est d'ailleurs commémoré au 18 juillet dans le nécrologe de Corbie comme abbé de Corvey (98).

L'inventaire du XVII ${ }^{\text {e }}$ siècle des reliques de Stavelot par François Laurenty mentionne une relique de saint Adélard, abbé de Corbie († 827), curieusement rangé parmi les martyrs (99).

\section{CORNELIMÜNSTER [24] (100)}

Cf. supra les actes de confraternité.

\section{DeUTZ, Saint-Héribert [27]}

Aucune trace dans le livre des confraternités de Deutz du XII ${ }^{e}$ siècle (101). En 1780, Stavelot vendit à Deutz ses droits et revenus à Waldorf (102).

(97) Aucune trace de confraternité entre Stavelot et Corbie (France, Somme), ni mentions de moines; Corbie est pourtant unie en confraternité avec de nombreux établissements, voir Paris, BibliothèQue NATIONALE, Manuscrits Latins 17767, 17768 et 17770, d'après Lemaitre (J.-L.), Répertoire, op. cit., n' 2008-2015. Sur Corvey, cf. supra p. 111112.

(98) Paris, Bibliothèue Nationale, Manuscrit Latin 17767 f. 176v. : Wibaldus $a b b(a s)$ nove Corbeie.

(99) GEORGE, Les reliques de Stavelot-Malmedy, op. cit., p. 94 ; une élévation de ses reliques eut lieu vers 1036 vraisemblablement et des œuvres hagiographiques en son honneur composées dans la seconde moitié du XIe siècle ; cf. MORELLE (L.), La liste des repas commémoratifs offerts aux moines de l'abbaye de Corbie (vers 986/989) : une nouvelle pièce au dossier du "Patrimoine de saint Adalhard »?, ReVUe belGe DE PHILOLOGIE \& D'HISTOIRE, t. LXIX, 1991, p. 280-281.

(100) Un des rares lieux sans mention du titulaire de l'église.

(101) Albers (B.), Das Verbrüdenungsbuch der Abtei Deutz, Studien und MrTteILunGEN AUS DEM BENEDICTINER-ORDEN, t. XVI, 1895, p. 96-104, qui recense des confraternités avec Siegburg, Saint-Martin, Saint-Maurice et Saint-Pantaléon de Cologne, Brauweiler, Mönchengladbach, Saint-Laurent et Saint-Jacques de Liège, Maria-Laach, Saint-Eucher et Saint-Maximin de Trèves, Disibodenberg, Saint-Paul d'Utrecht, Schönau, Odenheim, Feuchtwangen, Grafschaft, Saalfeldt, Springiersbach, Marienfeld, Steinfeld, Verdun, Cornelimünster, Werden, Halle, Hildesheim, Corvey, Schinna, Afflighem, Cluny, Abdinghof, Lorsch, Flechdorf, Breitungen, Hirsau, Saint-Blaise et Saint-Georges en Forêt Noire, Saint-Gilles à Nüremberg, Nonnenwerth, Rindorp, Essen, Saint-Jacques à Wurzbourg.

(102) BaIX, Reims et Trèves, op. cit., p. 21. 
15. DinANT, Saint-Perpète [11]

A propos du titre de l'église :

$\mathrm{Au} \mathrm{VII}{ }^{e}$ siècle, l'évêque Perpète aurait été enseveli à Dinant dans l'église Saint-Vincent. Le dossier hagiographique est à reprendre entièrement. Avant 1250, le corps de l'évêque est transféré dans l'église Sainte-Marie, abbatia à l'origine devenue collégiale, qui va porter le double vocable de Notre-Dame et Saint-Perpète et obtenir des droits curiaux (103).

Il n'y a pas de relique de saint Perpète à Stavelot (104).

A propos des rapports entre Stavelot et Dinant: en 824, Stavelot bénéficie à Dinant d'une donation significative (HR 27) ; Stavelot ne payait aucune taxe et possédait 16 parcelles urbaines - sedilia - petites unités foncières destinées à la construction de maisons (105); au XI' siècle, le comte de Namur est avoué de bono sancti Remacli à Dinant (106).

16. ECHTERNACH, Saint-Willibrord [34]

On ne trouve aucune mention explicite des liens de confraternité dans les sources luxembourgeoises (107).

(103) Lhoest-Gaier (J.), L'évolution topographique de la ville de Dinant au Moyen Age, Bruxelles, 1964, p. 66-67 (Pro Crvitate, Collection Histoire, Série in-8 ${ }^{\circ}$, no 4).

(104) HAYOT (E.), La collégiale Notre-Dame à Dinant, Bulletin DE LA COMMISSION Royale DES MONUMENTS \& DES SiTES, t. II, 1950, p. 9-75.

(105) Despy (G.), Note sur le "portus» de Dinant aux IX'et $X I^{e}$ siècles, Melanges J. F. NIERMEYER, Groningue, 1967, p. 61-69.

(106) Cf. le "record » des droits du comte de Namur à Dinant, rédigé peut-être vers 1061 (KUPPER (J.- L.), Une "conventio » inédite entre l'évêque de Liège Théoduin et le comte Alber II de Namur (1056-1064), Bulletin DE LA COMMission ROYALE D'Histoire, t. CXLV, 1979, p. 11), publié par Rousseau (F.), Actes des comtes de Namur de la première race 946-1196, Bruxelles, 1936, p. 87-91, n' 1 (CRH in-4 ${ }^{\circ}$, Recueil des Actes des princes belges).

(107) Plusieurs confraternités sont relevées par STEFFEN (A.), Das älteste erhaltene Obituar der Abtei Echtemach, (HEMECHT, t. XIV, 1961, p. 5-102).

Rien non plus dans LIEBAERT (P.), Notice sur 43 manuscrits d'Echtemach consenvés à la Bibliothèque Nationale de Paris, HЕмecht, t. XXXVII, 1985, p. 53-74. 
Par contre, dans un obituaire d'Echternach rédigé au XII ${ }^{e}$ siècle, sont commémorés 91 moines de Stavelot et 41 de Malmedy (108).

Le calendrier en marge d'un autre obituaire d'Echternach inscrit au 3 septembre Mansueti et Remacli (109). Outre l'obituaire, un manuscrit conservé à Paris comprend aussi un martyrologe du XII ${ }^{\text {e }}$ siècle où est mentionnée la fête de saint Remacle (110). La Saint-Remacle est inscrite au début du XI ${ }^{\mathrm{e}}$ siècle au calendrier d'un sacramentaire d'Echternach (111) et une Vie du saint était conservée à l'abbaye (112). On notera, en passant, l'influence exercée sur le plan artistique par Echternach sur l'enluminure du collectaire de Thierry de Stavelot (113).

\section{FLORENNES, Saint-Jean-Baptiste [14]}

Aucune information (114), si ce n'est que l'autel de Sainte-Marie dans la crypte de Stavelot, consacré en 1046, comprenait des reliques

(108) Paris, Biblothèque Nationale, Manuscrit Latin 10158; les nombres de moines résultent d'un calcul que nous avons effectué dans l'édition de STEFFEN, op. cit.. Des fragments d'un autre obituaire du XIII' siècle conservé à la Bibliothèque Nationale de Luxembourg (Fragments du Manuscrit $n^{\circ} 1$ ) mentionnent deux moines de Stavelot (Cf. VAN Wer VeKe (N.), Catalogue descriptif des manuscrits de la Bibliothèque de Luxembourg, Luxembourg, 1894).

Les obituaires d'Echternach font encore actuellement l'objet de recherches (Cf. FERRARI (M.C.), Sancti Willibrordi venerantes memoriam. Echtemacher Schreiber und Schriftsteller von den Angelsachsen bis Johann Bertels. Ein Uberblick, Luxembourg, 1994, p. 87-88: Zu den Echternacher Obituaren) et il nous a été malheureusement impossible d'en apprendre davantage de la part des chercheurs.

(109) LuXembourg, Bibliothéqu Nationale, Manuscrit 136, manuscrit du XVI ${ }^{c}$ siècle complété jusqu'à la Révolution ; cf. PETERS, Das Obituarium der Abtei Echtemach, Publications de la Section Historique de l'INSTITUt royal Grand-Ducal de LUXEMBOURG, t. XXVII, 1872, p. 163.

(110) Paris, Biblotothèue Nationale, Manuscrit Latin 10158 ; cf. Baix (Fr.), Saint Remacle et le Luxembourg, FolkLore StaVelot-Malmedy, t. XVII, 1953, p. 32.

(111) Paris, Bibliothèque Nationale, Manuscrit Latin 9433, d'après Miesges (P.), Der Trierer Festkalender. Seine Entwicklung und seine Verwendung zu Urkundendatierungen, Trèves, 1915, p. 16 et 82.

(112) REINERS (Ad.), Les manuscrits de l'ancienne abbaye d'Echternach consenvés à la Bibliothèque Nationale de Paris, PUBLICATIONS DE LA SECTION HISTORIQUE DE L'INSTITUT GRAND-DUCAL DE LUXEMBOURG, t. XL, 1889, p. 13-52.

(113) Cf. MASAI (Fr.), Les manuscrits à peintures de Sambre et Meuse aux XIc et XII siècles, Cahiers de Ctvilisation Médievale, t. III, 1960, p. 184.

(114) Florennes est unie en confraternité avec Moulins, Villers, Broqueroie et SaintMartin de Tournai (Berlière (U.), Abbaye de Florennes, Monasticon Belge, t. I, Provinces de Namur et de Hainaut, 1897, p. 5-14 et suppl. p. 153-158); avec Saint-Laurent de Liège en 1446 (LièGe, Archives de l'EvEchE, G III 3, Cartulaire de Saint-Laurent, 
de saint Gengulphe. Le patron de Florennes fait aussi partie de l'invocation de la chapelle de l'infirmerie de Stavelot qui fut consacrée en 1563 (115).

\section{GAND, Saint-Pierre [43]}

Aucune information, ni dans la liturgie, ni dans les nécrologes (116). Everhelm, disciple de Poppon, fut abbé de Saint-Pierre sur le MontBlandin (117).

A Gand, mais à l'abbaye Saint-Bavon, on trouve mention de reliques de saint Remacle dans le Breviarium de thesauro sancti Bavonis quod invenerunt fratres remansisse post Nordmannicam infestationem, qui date de 851-864 (118).

\section{GeMblouX, Saint-Pierre [19]}

Aucune mention dans les sources de Gembloux (119).

Wibald est parmi les témoins d'une charte pour Gembloux le 28 décembre $1152(120)$.

t. II, f. CCCXXIX et DARIS (J.), Extraits du Cartulaire de Saint-Laurent, Bulletin DE LA SOCIETE D'ART \& D'HISTOIRE DU DIOCESE DE LIĖGE, t. II, 1882, p. 162). En 1680, Florennes renouvelle sa confraternité avec Saint-Jean de Liège et des reliques de Jean-Baptiste sont envoyées à Liège (LAHAYE (L.), Inventaire analytique des chartes de la collégiale de Saint-Jean l'Evangéliste à Liège, t. II, 1933, p. 316). Cf. aussi KUPPER (J.-L.), Florennes, LEXIKON DES MTTTELALTERS, t. IV-3, Munich, 1987, col. 552- 553.

(115) GeORGE, Les reliques de Stavelot-Malmedy, op. cit., p. 20, 78 et 84.

(116) Monsieur Cyriel Vleeschouwers nous a très aimablement écrit qu'il ne voyait aucune autre information à nous fournir sur ce sujet. Cf. aussi FAYEN (A.), Liber traditionum Sancti Petri Blandiniensis, Gand, 1906.

(117) Cf. infra Hautmont.

(118) BAIX, Saint Remacle. Culte \& reliques (I), op. cit., p. 16 ; HUYGHEBAERT (N.), Une translation de reliques à Gand en 944. Le Sermo de Adventu Sanctorum Wandregisili, Ansberti et Vulframmi in Blandinium, Bruxelles, CRH in- $8^{\circ}, 1978$, et DE CleRCQ (G.), Brugge als toevluchtsoord tijdens de Noormannenninval van 851, BRUGS OMMELAND, t. XXVIII, 1988, p. 131-139.

(119) WAUTERS (A.), Fragments inédits concernant l'ancienne abbaye de Gembloux, Bulletin De la Commission RoYale D'Histoire, t. II, 1875, p. 271-273. Gembloux est unie en confraternité avec Saint-Remi de Reims, Brogne, Villers, et Saint-Martin de Tours (Roland (C. G.), Recueil des chartes de l'abbaye de Gembloux, Gembloux, 1921, p. 17-18, 69-70, 96 et 146-147).

(120) Roland, op. cit., p. 64. 
Mention de saint Guibert, patron de Gembloux, au 13 août dans le calendrier de Malmedy (121).

\section{Gorze, Saint-Gorgon [40]}

Aucun moine de Stavelot-Malmedy n'est commémoré dans l'obituaire de Gorze, si ce n'est l'abbé Odilon de Stavelot, issu du monastère lorrain (122). Aucune relique stavelotaine à Gorze (123).

\section{Hautmont, Saint-Pierre [49]}

Aucune mention de confraternité (124).

Everhelm, disciple de Poppon et co-auteur de la Vita Popponis, fut abbé de Hautmont, puis, en 1053, abbé de Saint-Pierre sur le MontBlandin à Gand. La mémoire de Poppon reste vivace à l'abbaye (125). Le 23 septembre 1634, le bras droit de saint Poppon fut envoyé à Hautmont (126).

Le dépouillement des autres sources n'a rien apporté (127).

(121) ARChives de l'ÉTAT a Liège, Fonds de Stavelot-Malmedy, I, 538, éd. par HALKIN (J.), Inventaire des archives de l'abbaye de Stavelot-Malmedy consenvées à Düsseldorf, Bruxelles, Liège, Londres, Berlin, Paris, Hanau..., Bulletin de la Commission Royale D'Histolre, 5 série, t. VII, 1897, p. 289-295, rééd. et commenté dans notre thèse.

(122) PARISSE (M.), Le nécrologe de Gorze. Contribution à l'histoire monastique, Nancy, 1971 (ANNALES DE L'EST, Mémoire no 40), p. 87 et (L') abbaye de Gorze au Xe siècle. Etudes réunies par M. PARISSE \& O.G. OEXLE, Nancy, 1993. Cf. aussi Hallinger (K.), op. cit., p. 64-67 et MARGUE (M.), Aspects politiques de la "réforme " monastique en Lotharingie. Le cas des abbayes de Saint-Maximin de Trèves, de Stavelot-Malmedy et d'Echternach (934-973), REVUE BÉNÉDICTINE, t. XCVIII, 1988, p. 31-61.

(123) Cf. Notae Gorzienses, éd. Wattenbach (W.), MGH, SS, t. XV, p. 974-977.

(124) Hautmont est unie à Saint-Ghislain (FAIDER, Mons, op. cit., $\mathrm{n}^{\circ} 358$, p. 117) et à Saint-Michel (Aisne), fraternité renouvellée en 1203 (MIGNON, Hautmont et son abbaye, Hautmont, 1895, p. 124-126). Cf. aussi Devillers (L.), Cartulaire de l'abbaye d'Hautmont. Description analytique de cartulaires et de chartriers accompagnée du texte de documents utiles à l'histoire du Hainaut, t. III, Mons, 1867, p. 127. Anne-Marie Helvétius s'est occupée du cas d'Hautmont dans un ouvrage qu'elle annonce dans son article Hagiographie et architecture en Basse-Lotharingie médiévale, Actes des VII' Journées Lotharingiennes, Luxembourg, 30-31 octobre 1992, Productions et échanges artistiques en Lotharingie médiévale, Luxembourg, 1994, p. 30, dont nous n'avons pas encore pu prendre connaissance.

(125) Brasseur (Ph.), op. cit., 1648, p. 98.

(126) LEgRAND, op. cit., p. 25 et BRASSEUR, op. cit..

(127) Voir notamment LECLERCQ (Dom J.), Les manuscrits de l'abbaye d'Hautmont, SCRIPTORIUM, t. VII, 1953, p. 59-67 et t. IX, 1955, p. 107-109. 
Le corps de saint Marcel, pape et martyr, est conservé à Hautmont. L'abbé Ursion (1054/1058-1079) avait écrit une Vie du pape Marcel, le récit de l'Inventio de ses reliques ainsi que ses Miracles (128). Des reliques de saint Marcel sont présentes à Lierneux (XI' siècle) et à Stavelot (XII'e siècle ?) sans que l'on puisse affirmer qu'il s'agisse à coup sûr du même saint (129).

\section{Helmarshausen, Saint-Pierre [41]}

Des reliques de saint Remacle sont présentes à Helmarshausen à la fin du $\mathrm{XI}^{\mathrm{e}}$ siècle et la fête du saint $\mathrm{y}$ acquiert une grande importance (130). Depuis la fin du XIe siècle des liens étroits unissent les deux établissements (131). Reinhard, le précepteur de Wibald, était moine d'Helmarshausen (132).

\section{Houffalize, Sainte-Catherine [57]}

L'obituaire du Prieuré de Houffalize de l'Ordre du Val-des-Ecoliers, rédigé depuis le début du XVIII' siècle jusqu'à la fin de l'Ancien Régime (133), porte mention d'une soixantaine de moines de Stavelot et

(128) Mrsonne (D.), Une nouvelle forme des Annales d'Hautmont (1096-1124), REVUE BENEDICTINE, t. XCIV, 1984, p. 229-244. Cf. aussi DolbeAu (Fr.), Poème inédit en l'honneur d'un copiste d'Hautmont, SCRIPTORIUM, t. XXXVI, 1982, p. 252-254.

(129) GEORGE, Les reliques de Stavelot-Malmedy, op. cit., p. 50, 56 et 111.

(130) BAIX, Saint Remacle. Culte \& reliques (II), op. cit., p. 21, et LAPIĖRE (M.-R.), La Lettre omée dans les manuscrits mosans d'origine bénédictine (XIc-XII siècles), Paris,

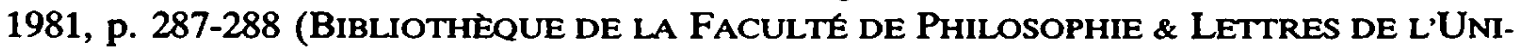
versite de liege, Fasc. CCXXIX). Cf. aussi Pfaff (F.), Die Abtei Helmarshausen, ZeITSCHRIfT des VEREINS FÜR Hessische Geschichte UND LANDESKUNDE, t. XLIV, 1910 , p. $188-286$ et t. XLV, 1911, p. 1-80.

(131) Cf. JAKOBI, op. cit., p. 278.

(132) Fait connu par la correspondance de l'abbé, cf. Silvestre (H.), Notes sur la controverse de Rupert de Saint-Laurent avec Anselme de Laon et Guillaume de Champeaux, Saint-Laurent de liége. Église, Abbaye et hopttal milttaire. Mille ans d'HisTOIRE, éd. Lejeune (R.), Liège, 1968, p. 72.

(133) Ed. Vannérus (J.), AnNales de l'Institut archeologioue du luXemBOURG, t. LVI, 1925, p. 5-51. 
de Malmedy; à certaines notices est rappelée la fraternité entre les établissements : [abbatia] cum qua habemus associationem (134).

\section{HuY, Saint-Sépulcre [10]}

Il s'agit du Neufmoustier-lez-Huy dont le titre Ecclesia sanctissimi Sepulchri Domini beatique Johannis Baptiste est attesté en 1146 (135).

Les listes de reliques du Neufmoustier ne mentionnent pas Remacle (136). Quant aux confraternités, on connaît seulement par l'intermédiaire de l'obituaire du Neufmoustier celle avec Springiersbach (Diocèse de Trèves), à la fin du XII ${ }^{e}$ siècle (137).

\section{KAISERSWERTH, Saint-Suibert [28]}

Dans le Kalendarium necrologicum Werdinense, au 4 septembre : Memoria fratrum sancti Remacli (138).

(134) Houffalize est uni en confraternité avec Géronsart (1717) et le Val-des-Ecoliers à Mons (1722) (VAnnérus, op. cit., p. 41-43). Pour la bibliographie, cf. PetrT (R.), Prieuré du Val-des-Ecoliers à Houffalize, MONASTICON Belge, t. V, Province de Luxembourg, 1975, p. 297-337 et le Catalogue de l'exposition Ant religieux, histoire, archéologie au pays de Houffalize, Houffalize, 1985.

Aux Archives de l'État à Saint-Hubert est conservé le cartulaire du Prieuré d'Houffalize (Fonds, $n^{\circ} 177$ ) qui contient aux folios CIr-CVIr un obituaire de 1390 , qui n'était pas le plus ancien comme en témoigne un jugement de la cour prévôtale d'Ardenne en date du 25 juin 1374 (Inventaire, p. 123, reg. 118); cet obituaire de 1390 est inédit et n'est pas mentionné par Vannérus dans son édition du nécrologe du XVIII' siècle, bien qu'on en retrouve naturellement des mentions. Le nécrologe édité par Vannérus porte le no 191 dans l'inventaire actuel du fonds. Il se termine par la copie des accords de confraternité entre Houffalize, Géronsart et Mons. Une troisième confraternité fut conclue en 1659 avec Bernardfagne ( $\mathrm{n}^{\circ} 200$ du fonds). Le 11 février 1421, trois religieux originaires de Stavelot concluent un accord avec les religieux d'Houffalize, leur reconnaissant le droit d'exiger une rente de trois muids d'épeautre au grenier de Bernardfagne (Inv., regeste $n^{\circ}$ 142). Tous ces renseignements nous ont été très aimablement transmis par Monsieur Roger Petit que nous remercions très vivement.

(135) Hansotte (G.), Abbaye de Neufmoustier, Monasticon belge, t. II, Province de Liège, 1955, p. 283 et IDEM, Inventaire des archives de l'abbaye de Neufmoustier, Bruxelles, 1960.

(136) Nous avons leur édition en préparation; en attendant cf. notre article De l'intérêt, op. cit., p. 512.

(137) DEREINE (Ch.), Les chanoines réguliers au diocèse de Liège avant saint Norbert, Bruxelles, 1952, p. 146-147 (ACADémie Royale de Belgique. Classe des lettres \& DES SCIENCES MORALES \& POLITIQUes, Mémoires in- $8^{\circ}, \mathrm{t}$. XLVII).

(138) Ed. Böhmer (J. F.), Fontes Rerum Germanicarum, Stuttgart, t. III, 1853, p. 390. 
Aucune mention de reliques à Stavelot de saint Suibert, le patron de Kaiserswerth (139), ni de mention liturgique (140).

\section{LAACH [35] (141)}

Aucun moine de Stavelot-Malmedy n'est commémoré dans l'obituaire tardif de Maria Laach (142), dont le calendrier, inscrit en marge, ne porte pas mention de la fête de saint Remacle (143).

Par contre, Remacli episcopi et confessoris est inscrit au 3 septembre au calendrier d'un sacramentaire du XII ${ }^{e}$ siècle de Laach (144). Remacle est aussi nommé dans le commun des saints (145). Cependant on ne trouve aucune relique du saint dans les autels de l'abbatiale (146).

\section{LIĖGE, Saint-Gilles en Publémont [9]}

Aucune mention réciproque de la confraternité (147).

(139) Kaiserswerth est unie en confraternité avec Aix, Maastricht, les Franciscains, les Dominicains et l'Ordre de Notre-Dame du Mont-Carmel (Cf. KeEleter (H.), Urkundenbuch des Stiftes Kaiserswerth, Bonn, 1904, p. 46, 70-71, 76, 98, 160 et 234).

(140) Coens (M.), Une fiction d'origine rhénane : S. Suibert, évêque-martyr de Bethléem, Analecta Bollandiana, t. LXVI, 1948, p. 91- 117.

(141) Un des rares lieux sans mention du titulaire de l'église.

(142) WEGELER (J.), Kalendarium defunctorum monasterii beatae Mariae vinginis in Lacu, ANNALEN DES HISTORISCHEN VEREINS FUR DEN NIEDERRHEIN INSBESONDERE DIE Alte Erzdiócese KólN, t. XXVI-XXVII, 1874, p. 268-306.

(143) A noter les liens privilégiés du monastère avec Saint-Maximin de Trèves et Affligem. Cf. aussi ResMINI (B.), Die Benediktinerabtei Laach, op. cit., p. 198-203, Reliquien, sans toutefois qu'il nous ait été possible de retourner aux sources.

(144) Frank (H.), Das älteste Laacher Sakramentar, ENKAINIA. GESAMMELTE ARBEITEN ZUM 800 JÄHRIGEN WEIHEGEDĀCHTNIS DER ABTEIKIRCHE MARIA LAACH AM 24. August 1956, éd. Emonds (H.), Düsseldorf, 1956, p. 284.

(145) IBIDEM, p. 290.

(146) OSLENDER (F.), Das Laacher Hochaltarciborium, IBIDEM, p. 304-346 et OTTEN (Cl.), Die Altäre der Laacher Kirche, IBIDEM, p. 347-364. L'autel de la Vierge à Maria Laach recèle entre autres des reliques de saint Quentin (Quinti) selon OTTEN, op. cit., p. 360 et de saint Quirin (Quirini) selon les Dedicationes Monasterii Lacensis, éd. HoLDEREGGER (O.), MGH, SS, t. XV 2, p. 971 ; s'agirait-il du Quirin de Malmedy?

(147) LECOMTE (Fr.), Inventaire analytique des archives de l'abbaye de Saint-Gilles à Liège, Bruxelles, Archives Générales du Royaume, 1976. Saint-Gilles est associée en fraternité (cf. Dereine (Ch.) \& Russe (J.), Abbaye de Saint-Gilles, Monasticon belge, t. II, Province de Liège, 1955, p. 304, 306, 307, 309 et 317) avec Saint-Laurent de Liège (XII' siècle, renouvelé en 1641), avec Saint-Pierre de Liège (1128, renouvelé en 1242, cf. PONCELET (Éd.), Note sur le Liber chartarum de l'église collégiale de Saint-Pierre à Liège, Bulletin de la COMMission ROYALE D'Histoire, t. CIV, 1939, p. 5-8), et avec le clergé secondaire à Liège (1258 cf. DURY (Ch.), Fraternités et clengé secondaire du diocèse de Liège au Moyen Age. Contribution à la protohistoire des assemblées représentatives, LE MOYEN AGE, t. XCVI, 1990, p. 287-316. 
Wibald entretint quelques relations avec l'abbaye de Saint-Gilles de Liège (148).

Saint Gilles est inscrit dans les litanies de Stavelot du XII ${ }^{e}$ siècle et des reliques du saint sont conservées à Stavelot et à Lierneux (149).

28. LIĖGE, Saint-Jacques-en-Ile [7]

Le 19 mars 1479, l'abbé de Saint-Jacques, Arnould de Berct envoya une lettre de confraternité à Jaspar, abbé de Stavelot-Malmedy (150). Halkin \& Roland répertorient le document sans l'éditer; nous l'avons retrouvé aux Archives de l'Etat à Liège et en donnons une édition cidessous en annexe 2.

Des relations sont attestées entre Saint-Jacques et Stavelot à propos d'Horion-Hozémont au début du XIV ${ }^{e}$ siècle et à propos de visites de Stavelot à la fin du $X V^{e}$ siècle (151).

L'abbé Erlebald ( +1193$)$ est commémoré au 11 mars dans l'obituaire de Saint-Jacques (écriture du XIII' ${ }^{e}$ siècle), ainsi qu'un Jean, coûtre de Malmedy au 30 mars (152).

(148) DEREINE-RUSSE, op. cit., p. 306 et en dernier lieu ReUter (Th.), Rechtliche Argumentation in den Briefen Wibalds von Stablo, FESTSCHRIFT H. FuHRMANN, éd. MoRDEK (H.), Tübingen, 1991, p. 251-264.

(149) GEORGE, Les reliques de Stavelot-Malmedy, op. cit., p. 17, 56 et 89.

(150) Dom Berlière (Saint-Jacques, Monasticon, op. cit., p. 10, 11, 16, 18, 23) signale plusieurs confraternités de Saint-Jacques : Liège, Saint-Paul (1113), Cluny (1157), Liège, Saint-Laurent (1168; éditée par STIENNON (J.), Etude sur le chartrier et le domaine de l'abbaye de Saint-Jacques de Liège (1015-1209), Paris, 1951, p. 443-444 (BIBLIOTHÉque de la Faculte de Philosophie \& LetTres de L'Universite de Liege, Fasc. CXXIV)), Ordre du Carmel (1315), Echternach (1356), Tournai, Saint-Martin (1472), Liège, BonsEnfants (1490). Sur Saint-Jacques et Saint-Paul, cf. DuRY, op. cit., p. 316. Le manuscrit 54 de la Bibliothèque de l'Université de Liège $\left(f^{\circ} 229 \mathrm{v}\right)$ garde copie d'une charte de confraternité avec Egmond en 1486 (STIENNON (J.), Le manuscrit saintronnaire du Liber Ordinarius Sancti Jacobi Leodiensis, SCRIPTORIUM, t. V, 1951, p. 96).

(151) Cf. HR à l'index.

(152) Berliete (U.), Fragment d'un nécrologe de Saint-Jacques à Liège, BULLETIN DE LA COMMISSION ROYALE D'HistoIRE, t. XCV, 1931, p. 226 et 229. 
$\mathrm{Si}$, bien entendu, des reliques des deux saints Jacques, le Mineur et le Majeur, sont présentes à Stavelot, sans que l'on puisse à coup sûr en déterminer la provenance, il n'y a par contre aucune trace de reliques stavelotaines à Saint-Jacques (153).

29. LIĖGE, Saint-Lambert [5]

Aucune mention réciproque de la confraternité (154).

L'obituaire de Saint-Lambert mentionne les abbés Guntmar ( ? 12 janvier), Poppon (24 janvier), Poppon II (26 juillet) et Ravenger (9 novembre), sans compter les abbés laïcs Alard et Regnier-au-LongCol (155).

Des reliques de saint Remacle sont mentionnées en 1489 lors de l'ostension des reliques de la cathédrale de Liège (156).

Des reliques de saint Lambert sont présentes à Stavelot. Le souvenir de l'exil du saint évêque dans l'abbaye ardennaise est très présent, de part et d'autre, pendant tout l'Ancien Régime (157).

(153) Cf. nos articles Un reliquaire, "souvenir » du pèlerinage des Liégeois à Compostelle en 1056 ? REVUE BELGe d'ARCHÉologie \& D'Histoire De L'ART, t. LVII, 1988, p. 5-21, et, Documents inédits sur le trésor des reliques des abbayes bénédictines de Saint-Laurent et de Saint-Jacques de Liège (XI'-XVII'e siècles), Bulletin DE LA COMMISSION ROYAlE D'HISTOIRE, t. CLVIII, 1992, p. 1-49.

(154) Saint-Lambert était uni avec le chapitre d'Hildesheim en 1204, le Val SaintLambert en 1234, Aulne en 1235-6, Otterburg en 1250, Fosses en 1281, l'abbé et le chapitre général de l'Ordre des Prémontrés en 1288, et Verdun en 1297 (D'après Bormans (St.), Schoolmeesters (E.), et Poncelet (Éd.), Cartulaire de l'Eglise Saint-Lambert à Liège, t. I, 1893, p. 141, 335, 354, 594, t. II, 1895, p. 342, 446, 540 et t. VI, 1933, p. 11.

(155) Cf. L'Obituaire de la Cathédrale Saint-Lambert de Liège (XI'-XVe siècles), éd. MARChandisse (A.), Bruxelles, 1991, CRH in- $8^{\circ}$, p. 263.

(156) Cf. notre contribution au catalogue de Visé, op. cit., p. 79.

(157) GEORGE, Les reliques de Stavelot-Malmedy, op. cit., p. 39. 
30. LIĖGE, Saint-Laurent près des murs [8]

Aucune trace de cette confraternité avec Stavelot, par contre des renseignements sur celle avec Malmedy (158).

Sur le plan des relations personnelles, on pense bien sûr à l'action de Poppon à Saint-Laurent. Sa présence en 1034 à la cérémonie de consécration de l'abbatiale serait une invention du chroniqueur Renier de Saint-Laurent pour équilibrer le dossier de l'abbaye par rapport à Saint-Jacques (159).

Wibald défendit les intérêts de Saint-Laurent dans le conflit qui l'opposait à Saint-Gilles; les sources l'attestent; par contre on ne trouve aucune trace du séjour, supposé par la Gallia Christiana, d'Erlebald de Stavelot, comme novice à Saint-Laurent (160).

Seul Poppon est inscrit le 25 janvier au calendrier-obituaire provenant de Saint-Laurent (161). Remacle est commémoré au 3 septembre dans le fonds primitif du calendrier (XIc siècle) (162) mais aucune relique du saint n'est présente à l'abbaye (163). Faut-il mentionner celles de saint Laurent à Stavelot dont la provenance nous échappe ?

(158) Outre Malmedy, Saint-Laurent est unie en fraternité avec Saint-Jacques de Liège (1168, renouvelée en 1212, cf. YaNS (M.), Le cartulaire de l'abbaye de Saint-Laurentlez-Liège conservé au British Museum, BuLLETIN DE LA SOcIÉtE D'ART \& D'HISTOIRE DU Diocése DE LiĖGe, t. XLVII, 1967, no 12 p. $49-52$ et $n^{\circ} 42$ p. 110 et Silvestre (H.), Le Chronicon Sancti Laurentii Leodiensis dit de Rupert de Deutz. Etude critique, Louvain, 1952; p. 244), Saint-Nicaise de Reims (ca 1200), Cluny (1206) (BERLiere, Saint-Laurent, MoNASTICON, op. cit., p. 40-41), et Saint-Maximin de Trèves (Geuenich (D.), Eine unveröffentlichte Verbrüdenungsliste des 12. Jahrhunderts aus St. Maximin/Trier, RHEINISCHE VIERTELJAHRSBLATTER, t. XLI, 1977, p. 180-195), Florennes (Cf. supra), Saint-Hubert (1534, cf. Daris (J.), Notice sur Saint-Laurent de Liège, BulleTIN DE LA SOCIÉtE D'ART \& D'HISTOIRE DU DIOCESE DE LIEGE, t. II, 1882, p. 168) et le clergé secondaire (DURY (Ch.), op. cit.). Dom Berlière signale par ailleurs des mentions d'abbés et de religieux de Saint-Laurent dans les nécrologes de Saint-Trond et de Gladbach (BERLIÈkE, Saint-Laurent, MONASTICON, op. cit., p. 34).

La confraternité avec Malmedy est renouvelée en 1684, cf. DARIs, op. cit., t. II, p. 175 et ARCHIVES DE L'Évéché A LIĖGe, Cartulaire de Saint-Laurent, t. VII, f. 1r-v et 71v.

(159) Silvestre, Le Chronicon Sancti Laurentii, op. cit., p. 224 et 264.

(160) GeORGE, Les reliques de Stavelot-Malmedy, op. cit., p. 17.

(161) Coens (M.), Un calendrier-obituaire de Saint-Laurent de Liège, ANALECTA BOL LANDIANA, t. LVIII, 1940, p. 59 ; sur ce manuscrit cf. la bibliographie donnée dans notre article sur les trésors de Saint-Jacques et de Saint-Laurent, op. cit., p. 35.

(162) COENS, op. cit., p. 53.

(163) Cf. notre article sur le trésor de Saint-Laurent, qui comprend, par contre, des reliques de Quirin. 


\section{LIÈGE, Saint-Martin [6]}

Les seules relations attestées entre le chapitre de Saint-Martin (164) et Stavelot-Malmedy sont l'établissement en 1138 d'une rente à payer (165).

Aucune mention de relique de saint Remacle à Saint-Martin (166). L'église paroissiale dépendant de la collégiale était dédiée à saint $\mathrm{Re}$ macle ; sa première mention date de 1181 (167).

\section{LOBBES, Saint-Pierre [18]}

Aucune trace de cette fraternité à Lobbes (168) même si beaucoup de liens rattachent cette abbaye à Stavelot.

N'est-ce pas Hériger de Lobbes († 1007) qui va être chargé de réécrire la Vita Remacli? Grâce aux abbés Wérinfride de Stavelot (954980) et Héribert de Saint-Hubert, Notger put mettre fin aux différends qui existaient à Lobbes entre l'abbé et les moines (169). En 1097, Goderan de Lobbes réalisa la «Bible de Stavelot», précieux manuscrit et « orgueil des moines de Saint-Remacle » (170). C'est précisément dans

(164) Saint-Martin est unie aux autres collégiales de Saint-Jean et de Saint-Paul de Liège dès 1242 (D’après LAHAYE (L.), Inventaire analytique des chartes de la collégiale Saint-Jean l'Evangéliste à Liège, t. I, 1921, p. 55, 79 et 210, t. II, 1933, p. 316 et DURY (Ch.), op. cit.). La collégiale est unie avant 1200 en confraternité avec le chapitre de SaintMartin de Tours, cf. notre contribution Le culte des saints dans le Catalogue de l'exposition Saint-Martin. Mémoire de Liège, Liège, 1990, p. 110.

(165) SCHOONBROODT (J. G.), Inventaire analytique et chronologique des chartes du chapitre de Saint-Martin à Liège, Liège, 1871, $\mathrm{n}^{\circ} 3$.

(166) SCHOONBROODT, op. cit., et GOBERT (Th.), Les mues de Liège, réimpr. anast., Bruxelles, 1976, t. VIII, p. 19. Nous avons en préparation l'édition des listes de reliques de la collégiale, en attendant cf. notre contribution au Catalogue de l'exposition de SaintMartin, op. cit.

(167) Sur ses origines, voir notre contribution au Catalogue de l'exposition de SaintMartin, op. cit., p. 97-98.

(168) Une association de prières pour les défunts fut créée sous l'abbatiat d'Aletran (960-965). Cf. WARICHEZ (J.), L'abbaye de Lobbes depuis les onigines jusqu'en 1200. Etude d'histoire générale et spéciale, Louvain-Paris, 1909, p. 166.

(169) Berlietre (U.), Abbaye de Stavelot-Malmedy, Monasticon belge, t. II, Province de Liège, 1928, p. 77.

(170) «Le manuscrit faisait l'orgueil des moines de Saint-Remacle, qui le montraient avec bonheur aux visiteurs de distinction et le conservèrent jusqu'à la fin de l'Ancien Régime ", LAPIËRE, La lettre ornée, op. cit., p. 411-412.

Parmi ces visiteurs, Martène et Durand, cf. MARTÈne \& DuRAND, Voyage littéraire de deux religieux bénédictins [...], Paris, 1724, t. II, p. 149 sv.. 
ce manuscrit que sera par la suite consignée la liste des confraternités de l'abbaye que nous analysons ici. Goderan fut doyen à Stavelot (171). Parmi ces moines dont on connaît le passage d'un établissement à l'autre, Thierry, écolâtre dans les deux monastères et futur abbé de Saint-Hubert (172).

Des reliques de saint Ursmer et de saint Ermin, abbés de Lobbes, sont présentes dans l'autel de Sainte-Marie à Stavelot en 1046 (173). Saint Remacle semble absent du calendrier de l'abbaye (174).

\section{LUXEMBOURG [36] (175)}

C'est sans doute l'abbaye bénédictine de Luxembourg fondée en 1083 (176). On notera cependant que des reliques de saint Remacle sont déjà contenues dans l'autel de la chapelle castrale de Luxembourg en 987 (177).

\section{MALmedY, Saint-Pierre [1]}

L'interdépendance des deux monastères nous dispense de tout commentaire (178).

(171) MASAI, Manuscrits à peintures, op. cit., p. 189 n. 65.

(172) WARICHEZ, op. cit., p. 270.

(173) GEORGE, Les reliques de Stavelot-Malmedy, op. cit., p. 83-84.

(174) Calendrier non daté de Lobbes publié par Vos (J.), Lobbes, son abbaye et son chapitre, t. I, Louvain, 1865, p. 402.

(175) Un des rares lieux sans mention du titulaire de l'église.

(176) Margue (M.) \& Pauly (M.), Saint-Michel et le premier siècle de la ville de Luxembourg. Quelques réflexions sur l'apport de l'histoire religieuse à l'étude des origines de la ville, НЕмЕснт, t. XXXIX, 1987, p. 59. L'ancien obituaire de l'abbaye n'est plus conservé et celui du XVIII' siècle n'apporte aucune information sur notre sujet (STEFFEN (A.), Das Obituar der Münsterabtei S. Maria in Luxemburg, HЕМЕCHT, t. XIV, 1961, p. 103119).

(177) Muller (J.-Cl.), Zur textlichen Grundlage des Millenniums der Michaels-Kirche, HÉMECHT, t. XL, 1988, p. 463.

(178) La confraternité survit aux conflits, aussi graves soient-ils, comme entre SaintJacques et Saint-Laurent de Liège ; cf. notre article sur le trésor de ces deux abbayes, op. cit., p. 2. 
35. Malonne, Saint-Pierre [17]

Aucune mention de confraternités (179), ni de relique de saint Remacle (180).

36. METZ, Saint-Arnould [48]

Aucune mention de confraternité, ni de moines dans les obituaires messins (181).

Aucune relique de saint Arnoul à Stavelot-Malmedy; par contre le saint est présent dans les litanies du $X^{\mathrm{e}}$ siècle (182) et une Vita du saint évêque de la fin du XI $\mathrm{XI}^{\mathrm{e}}$ siècle fait partie des manuscrits de Malmedy (183). Aucune relique stavelotaine à Saint-Arnould (184).

\section{Metz, Saint-Clément [44]}

«En fait, on continua jusqu'au XI ${ }^{\text {e }}$ siècle à appeler Saint-Félix la basilique où reposait saint Clément ", évêque de Metz (185).

(179) BARBier (V.), Cartulaire de l'abbaye de Malonne, Louvain, 1886.

(180) Barbier (V.), Histoire de l'abbaye de Malonne, Namur, 1894 et Berlière (U.), Abbaye de Malonne, Monasticon Belge, t. I, Provinces de Namur et de Hainaut, 1897, p. $140-148$ et $186-188$.

(181) Informations aimablement transmises par Monsieur le Professeur Michel Parisse. Cf. aussi Klauser (Th.) \& Bour (R. S.), Un document du IX siècle. Notes sur l'ancienne liturgie de Metz et sur les églises antérieures à l'an mil, ANNUAIRE DE LA SOCIETÉ D'Histoire \& D'Archélogie de la Lorraine, Metz, t. XXXVIII, 1929, p. 602-606; Misonne (D.), Les membres du chapitre cathédral de Metz au $X^{*}$ siècle. Une liste destinée au "Liber Memorialis» de Saint-Amand?, MElanges J. STIEnNon, Liège, 1982, p. 495508. Saint Remacle est commémoré dans des bréviaires de Metz au XVc siècle, cf. LEROQUAIS, Bréviaires, op. cit., t. II, p. 235 et 254.

(182) Arnulfe: CoENS, op. cit., p. 228.

(183) VATICAN, Lat. 8565, cf. STIENNON (J.), Le scriptorium et le domaine de l'abbaye de Malmedy du Xe au début du XIII siècle d'après les manuscrits de la Bibliothèque Vaticane, BULLETIN DE L'INSTITUT HISTORIQUE BELGE DE ROME, t. XXVI, 1950, p. 15.

(184) Dedicationes ecclesiae S. Amulfi, MGH, SS, t. XXIV, p. 545-549.

(185) PICARD (J.-Ch.), Le recours aux origines. Les Vies de saint Clément, premier évêque de Metz, composées autour de l'an mil, RELIGION \& CULTURE AUTOUR DE L'AN Mil. Royaume Capetien \& Lotharingie. Actes du Colloque Hugues Capet 987-1987. La France de l'an mil, Paris, 1990, p. 292. 
Aucune relique de saint Clément à Stavelot-Malmedy; par contre saint Clément y est invoqué dans les litanies aux $\mathrm{X}^{e}, \mathrm{XI}^{e}$ et $\mathrm{XII}^{e}$ siècles (186), sans bien entendu pouvoir à coup sûr prétendre qu'il s'agisse du saint évêque de Metz.

38. METZ, Saint-Martin [45]

Le culte de saint Sigebert naquit dans cette église au XII ${ }^{e}$ siècle et se propagea de là à Malmedy puis à Stavelot (187).

Aucune autre mention (188).

39. METZ, Saint-Symphorien [39]

Des reliques de saint Symphorien sont présentes à Lierneux sans bien sûr prétendre à une quelconque influence ou provenance de Metz. Le saint est invoqué au $\mathrm{X}^{\mathrm{c}}$ siècle à Stavelot (189). Un texte De sancto Symphoriano est présent dans un manuscrit des $\mathrm{XI}^{\mathrm{e}}-\mathrm{XII}{ }^{e}$ siècles de Stavelot (190).

Aucune relique stavelotaine à Saint-Symphorien (191).

(186) COENS, op. cit., p. 226, 237 et 240.

(187) BAIX (Fr.), Le souvenir de saint Sigebert à Stavelot-Malmedy, FolkLORE STAVELOT-MALMEDY, t. XIV, 1950, p. 15-16 et notre notice dans le LeXIKON DES MITTELALTERS sur Sigebert III (sous presse).

(188) Des confraternités existaient entre les églises de Metz. Cf. Tabouillot (N.) \& FrancoIs (J.), Histoire générale de Metz par les religieux bénédictins [...], Metz, 1790, t. I, p. 513 et t. II, p. 98 et 440 .

(189) COENS, op. cit., p. 227.

(190) BHL 7967, Bruxelles, Bibliothèoue Royale, Manuscrit II, 1181, f. 267, cf. Michiels, op. cit., p. 93.

(191) LAGer, Saint-Symphorien de Metz, p. 208-215, 330-343 et 466-493 et PerTz in MGH, SS, t. IV, p. 671 sv.. 
40. METZ, Saint-Vincent [47]

Poppon de Stavelot a gouverné cette abbaye de Metz (192) où l'on croyait posséder des reliques du saint (193). L'écolâtre Folcuin de Stavelot y devint abbé en 1041 (194).

Vincent est invoqué dans les litanies des $\mathrm{Xe}$ et $\mathrm{XI}^{\mathrm{e}}$ siècles de Stavelot (195). Une passio sancti Vincentii martiris est présente dans un manuscrit des $\mathrm{XI}^{e}$ et $\mathrm{XII}^{e}$ siècles de Stavelot (196).

\section{MONT-CASSIN [56] (197)}

«Montis Sancti Cassini » doit être identifié avec le Mont-Cassin dont Wibald fut abbé (198).

Aucune autre information (199).

\section{NoYON, Saint-Eloi [3]}

D'après la Vita Remacli prima rédigée vers 830-840 (BHL 71137114), Remacle aurait fait profession monastique sous la conduite de saint Eloi, conseiller de Dagobert $I^{\text {er }}$ et futur évêque de Noyon

(192) En 1026, il opère comme abbé de Saint-Vincent un accensement de biens; cf. STUDER (R.), Catalogue des documents des archives de la Moselle antérieurs à 1101, ANNUAIRE DE LA SOCIETE D'HISTOIRE \& D'ARCHÉlOGIE DE LA LORRAINE, t. XXXII, 1923, p. 135. Cf. aussi KLAUSER-BOUR, op. cit., p. 535-537.

(193) L'évêque Thierry Ier ramena des reliques en 970 (Cf. Sigebert DE GEMbLouX, Vita Deoderici, ca. 1050-1060, éd. MGH, SS, t. IV, 1841, p. 473-476, STUDER, op. cit., p. 132 et 140, et commentaires dans PICARD, op. cit., p. 293 sv.) sans rapports avec notre propos.

(194) Berlière, Stavelot, Monasticon, op. cit., p. 79 et SChMidt-Chazan (M.), Sigebert de Gembloux, le Lotharingien, Publications de la Section Historique de L'INSTITUT GRAND-DUCAL LUXEMBOURGEOIS, t. CVI, 1991, p. 24.

(195) COENS, op. cit., p. 226 et 237.

(196) BHL 8631, BruXelles, Bibliothèque Royale, Manuscrit II 1181, f. 184v187v, cf. MiCHIELS, op. cit., p. 93.

(197) Un des rares lieux sans le titulaire de l'église.

(198) La forme semble partout unique; ailleurs dans les chartes éditées par HR (t. I, p. 337 1. 11), le Mont-Cassin apparaît sous la forme "Mons Cassinus ».

(199) Monsieur H. E. J. Cowrey d'Oxford nous a très aimablement répondu qu'il ne voyait rien d'autre à ajouter. Il ne connaît aucun culte de Remacle au Mont-Cassin, ni aucune étude sur les confraternités de l'abbaye. Dell'OMO (M.A.), Montecassino, LeXIKON DES MitTELALTERS, t. VII, 1992, col. 785-790. 
(† 659) (200). Le souvenir de cette profession reste présent chez J. Levasseur au XVII ${ }^{e}$ siècle (201). Historiquement en tout cas, Eloi choisit Remacle comme abbé de Solignac en 632 et les liens entre les deux hommes furent étroits.

A Stavelot, un autel est dédié uniquement à saint Eloi (202).

\section{PADERBorn, Saint-Paul [37]}

Le nécrologe d'Abdinghof ne rappelle la mémoire d'aucun moine de Stavelot (203).

\section{PrüM, Saint-Sauveur [33]}

Cf. supra les actes de confraternité (204).

45. REIMS, Saint-Nicaise [39]

La fête de saint Remacle est au calendrier du monastère (205). Des reliques de saint Nicaise, évêque-martyr de Reims († 407) et de sa sœur Eutropie sont présentes à Stavelot dès le $\mathrm{XI}^{\mathrm{e}}$ siècle (206).

(200) BAIX (Fr.), Nouvelles recherches sur deux biographies de saint Remacle, MÉLANGES D'Histoire OFFerTS A ChARles MOELler, t. I, Louvain, p. 269.

(201) Annales de l'Eglise de Noyon, Paris, 1634, comme nous l'a indiqué Monsieur Philippe Racinet, auteur de la notice sur Noyon dans Abbayes et prieurés de l'ancienne France, op. cit., qui n'a toutefois trouvé aucune mention de relique de Remacle.

(202) GEORGE, Les reliques de Stavelot-Malmedy, op. cit., p. 78.

(203) Totenbuch Abdinghof, éd. LOFFLER (Kl.), ZEITSCHRIFT FÜR VATERLÄNDISCHE GESCHICHTE UND ALTERTUMSKUNDE, t. LXIII, 1905, p. 82-109.

(204) Aucun renseignement complémentaire dans MORIMOTo (Y.), Le commentaire de Césaire (1222) sur le polyptique de Prüm (893). Données pour le IX' ou le XIII siècle, Revue belge de Philologie \& D'Histoire, t. LXVIII, p. 261-290.

(205) BalX, Reims et Trèves, op. cit., p. 15-16.

Le Cartulaire de Saint-Nicaise de Reims (XIII siècle) (éd. par Cosse-DurLin (J.), Paris, Editions du CNRS, 1991) signale en 1193-1194 une association de prières avec SaintAmand ( $\mathrm{n}^{\circ}$ 251), en 1206 avec Saint-Remi ( $\mathrm{n}^{\circ}$ 250) et en 1246 avec Saint-Quentin ( $n^{\circ} 252$ ); des comptes rendus de cet ouvrage et des compléments d'informations sur les confraternités sont donnés par FALKenSTEIN (L.) dans FRANCIA, t. XIX, 1992, p. 310-314 et dans ZeITSChrifT DER SAVIGNY-STIFTUNG Für ReCHTSGESCHIChTE, t. CX, 1993, p. 433-447).

(206) GEORGE, Les reliques de Stavelot-Malmedy, op. cit., p. 81 et 111. 
46. ReIMS, Saint-Remi [38]

Cf. supra les actes de confraternité.

REIMS, Saint-Thierry, voir Verdun

\section{SAINT-AMAND en Pevèle (207) [50]}

Stavelot figure dans un relevé du $\mathrm{XV}^{\mathrm{e}}$ siècle des confraternités de Saint-Amand (208). Un office annuel pour les défunts était prévu le lendemain de la Sainte-Gertrude (17 mars), un septain à l'annonce de la mort d'un moine, un trentain pour un abbé ou un prieur. Ces obligations étaient réciproques (209).

Dans l'inventaire du trésor de Saint-Amand en 1513, on trouve l'indication diversae reliquiae $S$. Remacli (210). La fête de saint Remacle est absente du calendrier d'un missel du $X^{e}$ siècle à l'usage de l'abbaye (211).

Des reliques de saint Amand étaient conservées à Stavelot dès le $\mathrm{XI}^{\mathrm{e}}$ siècle et à Malmedy au $\mathrm{XVIII}^{e}$ siècle. Amand est invoqué dans les litanies de Stavelot aux $\mathrm{X}^{e}$ et $\mathrm{XI}^{\mathrm{e}}$ siècles et une Vita sancti Amandi est conservée dans un manuscrit du $\mathrm{X}^{\mathrm{e}}$ (?) siècle originaire de Stavelot (212).

(207) S. Amandi in Peveria, cf. édition en annexe. La forme Peveria ne peut être qu'une cacographie pour Pevela, forme transposée vraisemblablement du français et qui ne s'explique pas philologiquement; la forme normale est Pabula (renseignements aimablement transmis par Monsieur le chanoine Henri Platelle).

(208) ValenCienNes, Bibliothéoue municipale, Manuscrit $289, \mathrm{f}^{\circ} 98$ et verso.

(209) Renseignements aimablement communiqués par Monsieur Henri Platelle qui nous précise également que l'obituaire de Saint-Amand ne porte pas de commémoration de moines de Stavelot. Cf. Platelle (H.), Le temporel de l'abbaye de Saint-Amand des origines à 1340, Paris, 1962, en particulier p. 181-184; IDEM, La place de l'abbaye de Fécamp parmi les sociétés de prières de l'abbaye de Saint-Amand, L'ABBAYE BÉNÉdICTINE DE FECAMP, Ouvrage scientifique du XIII centenaire, Fécamp, 1958, p. 137-141 ; IDEM, Les relations entre Saint-Amand et Saint-Servais de Maastricht au Moyen Age, PUBLICATIONS DE la Société Historioue \& ARChÉlogioue daNS le LiMBOURG, 1980-1981, p. 352-366, en particulier p. $361 \mathrm{sv.}$.

(210) DESILVE (I.), Inventaire des reliques et objets de la sacristie de Saint-Amand, REVUE DE L'ART CHRETIEN, n. s., t. V, 1894, p. 323.

(211) Platelle (H.), Un missel du XVe siècle à l'usage de Saint-Amand, LtTteratUre \& Religion, Mélanges J. Coppin, Lille, 1966, p. 135.

(212) Coens, op. cit., p. 228 et 238 et BHL 332 : BRuXelles, Bibliothéque Royale, Manuscrit II 2568, f. 23-29v; cf. MiCHIELS, op. cit., p. 94. 
SAINT-THIERRY, voir Verdun.

48. SAINT-GOAR sur le Rhin [29]

Aucune relation particulière n'est attestée ((213).

49. SAINT-HUBERT en Ardenne [12]

Cf. supra les actes de confraternité.

Aucune mention de moine de Stavelot-Malmedy dans les fragments d'obituaire (214).

Un autel des saints Jacques et Remacle est fondé dans l'abbatiale de Saint-Hubert en 1270 (215). La fête de saint Remacle est inscrite au martyrologe du XII ${ }^{e}$ siècle de l'abbaye ardennaise (216). Le lectionnaire de Saint-Hubert des $X V^{e}-X^{e}$ siècles inclut la fête de saint Remacle (217).

Sans prétendre à coup sûr que le culte fut introduit via Saint-Hubert d'Ardenne, on notera que des reliques de saint Hubert sont présentes dès le XII ${ }^{e}$ siècle à Malmedy, qu'un autel est sous l'invocation du saint à Stavelot et que des reliques sont dans un autre autel en 1087 (218). Hubert est dans les litanies de Stavelot aux $X^{e}$ et $X I^{e}$ siècles (219).

50. SAINT-TROND en Hesbaye [21]

Le nécrologe de Saint-Trond de 1361 ne commémore aucun moine de Stavelot (220); au $1^{\text {er }}$ avril, le nécrologe de Saint-Trond, recopié vers

(213) Pauly (F.), Die Stifte St. Severus in Boppard, St. Goar in St. Goar, Liebfrauen in Oberwesel, St. Martin in Obenwesel, Berlin-New York, 1980 (Germania SACRA, nv. série, t. XIV).

(214) Retrouvés par G. Kurth, BulletiN de la Commission Royale d'Histoire, 5e série, t. VIII, 1898, p. 92-105.

Despy-Meyer (A.) \& Dupont (P.-P.), Notice sur l'Abbaye de Saint-Hubert, MonasTICON BELGE, V. Province de Luxembourg, Liège, 1975, p. 9-83.

(215) BAIX, Saint Remacle et le Luxembourg, op. cit., p. 25.

(216) Fransen (G.), Un manuscrit de Saint-Hubert en Ardenne à la Bibliothèque Nationale de Florence, REVUE BÉNÉDICTINE, t. LXXXVII, 1977, p. 195.

(217) FaIder (P.), Catalogue des manuscrits de Namur, op cit., Fonds de la Ville Cod. 2 p. 44, et BAIX, Luxembourg, p. 26.

(218) GeORGE, Les reliques de Stavelot-Malmedy, op. cit., p. 124.

(219) COENS, op. cit., p. 228 et 240.

(220) Liège, Bibliothèque de L'Universite, Manuscrit 326 C. 
1730 d'après un manuscrit ancien (221), retient un seul moine de Stavelot: Dominus Jacobus Margreve, monachus, sacerdos ac sacrae theologiae lector monasterii Stabulensis.

Poppon administra probablement l'abbaye qu'il confia par la suite à son disciple Gontran (après 1034) pour poursuivre la réforme (222). On notera aussi qu'en 1224, Jean de Xanten, abbé de Saint-Trond (1223-1228) fut désigné par le légat pontifical comme visiteur et réformateur de l'abbaye de Stavelot-Malmedy (223).

D'après les Gesta abbatum Trudonensium (224), en 1114, en voyage pour Metz, Raoul de Saint-Trond reçut l'hospitalité (hospitium) à Stavelot où il participa aux fêtes de commémoration de saint Remacle le 9 mai. Lors de la cérémonie, il se remémora les liens unissant Remacle et Trudon, révélés par leurs Vitae respectives, et implora le secours du saint patron ardennais dans les problèmes qui l'opposaient à l'avoué de son abbaye. Remacle exauça sa prière et Raoul obtint satisfaction (225).

Les patrons respectifs des abbayes étaient invoqués dans les litanies des deux établissements : à Stavelot, saint Trudon dans les litanies de la seconde moitié du XI' siècle (226) et dans celles du XVe siècle (227); à Saint-Trond, saint Remacle dans les litanies du XII' siècle (228). A Saint-Trond, saint Remacle figurait vers 1170 dans le lectionnaire de l'abbaye (229); à Stavelot existait un office de saint Trudon dans un bréviaire du XIII' siècle (230). On trouve des reliques de saint Trudon et de saint Libert à Stavelot et des reliques des sandales de saint $\mathrm{Re}$ macle à Saint-Trond (231).

(221) ANAlectes POUR SERVIR A l'Histoire ecClésiastiQue de BelgiQue, t. XVI, 1879, p. 377.

(222) Pieyns-Rigo (M.), Abbaye de Saint-Trond, Monasticon Belge, t. VI, Province de Limbourg, 1976, p. 32, et KUPPER, Eglise impériale, op. cit., p. 365 n. 87.

(223) Ibidem, p. 46.

(224) Ed. de Borman, t. I, 1877, p. 180- 182.

(225) Cf. aussi BAIX, Saint Remacle. Culte \& reliques (II), op. cit., p. 23-25.

(226) COENS, op. cit., p. 283.

(227) BruXelles, Bibliotheque royale, Manuscrit 6386-87, f. 177-178.

(228) CoENS (M.), Les saints particulièrement honorés à l'abbaye de Saint-Trond, ANALECTA BOLLANDIANA, t. LXXII, 1954, p. 119.

(229) Ibidem, p. 123 et 125.

(230) BRuXelles, BibliothęQUe Royale, Manuscrit $3092 \mathrm{f} .319 \mathrm{v}-321 \mathrm{v}$..

(231) George, Les reliques de Stavelot-Malmedy, op. cit., p. 132, BAIX, Saint Remacle. Culte \& reliques (II), op. cit., p. 25 et STIENNON (J.), Cluny et Saint-Trond au XII' siècle, Anciens Pays \& AssembleEs d'Etats, t. VIII, 1955, p. 57-86. 
51. SiegburG, Saint-Michel [30]

Aucune mention de cette confraternité à Siegburg (232). Aucun moine de Stavelot n'est commémoré dans le nécrologe de l'abbaye (233).

52. Solignac, Saint-Pierre [2]

Cf. supra les actes de confraternité (234).

Le rouleau funèbre de Hugues de Maumont, abbé de Solignac († 1240), fut présenté à Stavelot par le porteur Jean le 5 juin 1241, et nous donnons l'édition du texte en annexe 3.

TrÈVES

La fête de saint Remacle est inscrite au calendrier de plusieurs églises de Trèves dès le $\mathrm{XII}^{e}$ siècle et des manuscrits des XII ${ }^{e}-\mathrm{XIII}{ }^{e}$ siècles des Vita et Miracula Remacli sont répandus dans les milieux tré-

(232) Dans celles relevées par SFmmi.f. (I.), Die Klosterreform von Siegburg. Ihre Ausbreitung und ihr Reformprogramm im 11. und 12. Jahrhundert, Bonn, 1959, p. 328-333.

(233) Necrologium Sigebergense, éd. Eckertz (G.), ANNALEN DES Historischen VEREINS FUR DEN NIEDERRHEIN, t. VIII, 1860, p. 221-225 et WILBRAND (W.), Unbekannte Urkunde zur Geschichte der Abtei Siegburg, IBIDEM, t. CXXXVII, 1940, p. 73-97. Urkunden und Quellen zur Geschichte von Stadt und Abtei Siegburg, par WiSPLINGHOFF (E.), t. I, (948) 1065 - 1399, Siegburg, 1964.

(234) LemAîtRe (J.-L.), Les dépendances ecclésiastiques de l'abbaye de Solignac au Moyen Age, Bulletin de la Societé archélogique \& Historique du limousin, t. CXI, 1984, p. 96-121; IDEM, La bibliothèque et le chartrier de l'abbaye Saint-Pierre de Solignac, REVUE BÉNÉDICTINE, t. XCV, 1985, p. 321-338; IDEM, Le calendrier de l'abbaye Saint-Pierre de Solignac au XIVe siècle, CroYANCES, POUvoIrS ET SociETÉ. Études offertes à Louis Pérouas, Treignac, 1988, p. 253-263. 
virois (235). Une relique de saint Remacle est attestée le 26 janvier 1097 dans la dédicace d'un autel de Saint-Martin (236).

53. Trèves, Saint-Maximin [32]

On trouve trace de cette confraternité à Stavelot par un renouvellement en 1668 (237).

Les abbayes de Saint-Maximin et de Stavelot-Malmedy, déjà détenues aux $\mathrm{IX}^{\mathrm{e}}$ et $\mathrm{X}^{\mathrm{e}}$ siècles par les comtes-abbés Adélard, Regnier-auLong-Col et Gislebert ont été en rapports particulièrement intimes sous Poppon († 1048) dont un des derniers actes avait été de désigner son disciple Thierry pour prendre la direction de Saint-Maximin. Thierry fut nommé abbé de Stavelot en 1048. Folmar ( +1105$)$ occupa simultanément les abbayes de Stavelot et de Saint-Maximin. Odilon ( $+3-\mathrm{X}$ 954) et Ravenger († 9-XI-1008) sont inscrits au nécrologe de SaintMaximin, prouvant ainsi que Stavelot est compris dans l'aire de réforme lotharingienne (238).

L'obituaire de Saint-Maximin (239) porte mention de deux moines : Hezel de Stavelot enterré à Trèves (12 mai) et Azzo de Malmedy (16 novembre).

Aucune mention de relique stavelotaine à Saint-Maximin, par contre de nombreuses reliques de saint Maximin, évêque de Trèves à Malmedy (XII ${ }^{e}$ siècle) et à Stavelot (XI' siècle) (240). Saint Remacle est inscrit au calendrier de Saint-Maximin aux XIII ${ }^{e}$, XIV et $X^{e}$ siècles (241). Dans un bréviaire de 1600 à l'usage de Saint-Maximin "Remacli et Mansueti. Omnia in communi pluribus confessoribus ». Vita et Miracula Remacli sont présents dans un manuscrit du XI' siècle de Saint-Maximin de Trèves (242).

(235) BAIX (Fr.), Reims et Trèves, op. cit., p. 27-28.

(236) MGH, ss, t. XV 2, p. 1281. Cf. infra les archives de l'Époque Moderne.

(237) Liège, ArChIVEs de L'Etat, Chapitre de Stavelot, Reg. 28 p. 326 et Baix, Reims et Trèves, op. cit., p. 27.

(238) HAllinger, Gorze/Kluny, op. cit., p. 66.

(239) Ed. KRAUS (Fr. X.), BONNER JAHRBUCHER, t. LVII, 1876, p. 108-119.

(240) GEORGE, Les reliques de Stavelot-Malmedy, op. cit., p. 127.

(241) Miesges, op. cit., p. 83.

(242) Bruxelles, Bibliothèque royale, Manuscrit II 2611. 
54. TrèVES, Saint-Pierre [31]

\section{VAL SAINT-LAMBERT [15]}

Aucune mention de cette confraternité au Val (243).

Aucun moine de Stavelot, ni de Malmedy n'est commémoré dans les obituaires du Val (244).

Deux seules mentions de relations entre Stavelot et le Val-SaintLambert : en 1192-1197, l'abbaye de Stavelot donne au Val le passage de Meuse entre Ougrée et Sclessin (HR 280) (245); en 1328, le moine Jacques Troyens est autorisé à vivre à Stavelot par suite de la décadence du Val (246).

56-57. VERDUN [52-53]

56. S. Vedasti et Amandi Virdunensis

57. S. Theodorici in Insula Virdunensis

L'identification de ces deux établissements pose des problèmes. Le toponyme ne fait pas de doute : Virdunensis, Verdun, et nous opterions

(243) SCHOONBROODT (J. G.), Inventaire analytique et chronologique des archives de l'abbaye du Val-Saint-Lambert-lez-Liège, 2 t., Liège, 1875 et Suppl. par FAIRON, BulletiN DE LA. COMMISSION ROYALE D'HISTOIRE, t. LXXIV, 1905, p. 179-194 ; Schoonbroodt mentionne un seul acte de fraternité entre Saint-Jacques de Liège et le Val en 1752 (n' 2231 ).

(244) Liege, ARChives de l'Etat, Val Saint-Lambert, no 68 (1229-1547), 68 Bis f. 54v-55 et 69 et LONDRES, BRITISH LIBRARY, Add. 18495, renseignement aimablement communiqué par Monsieur Eef Overgaauw.

(245) C'est par abus de langage que nous parlons du Val Saint-Lambert pour ce droit de passage sur la Meuse; en réalité il s'agit d'une donation aux moines de Signy établis à Rosière, localité sur les bords de l'Ourthe, prédécesseurs de ceux du Val Saint-Lambert. Ces derniers récupéreront les donations antérieures et leur abbaye fut fondée en 1202 grâce à l'intervention de l'évêque de Liège Hugues de Pierrepont (VaN Derveeghde (D.), Le domaine du Val-Saint-Lambert de 1202 à 1387. Contribution à l'histoire rurale et industrielle du pays de Liège, Paris, 1955, p. 30-37).

(246) VAN DeRVEeghDE, op. cit., p. 101 et 155. 
pour une erreur du scribe à corriger comme suit : $S$. Vitoni (et Amandi) Virdunensis; S. Agerici in insula Virdunensis. Saint-Vanne de Verdun et Saint-Airy-en-l'Ile à Verdun.

Quant à Saint-Amand, on notera que c'est le titulaire de l'église paroissiale de l'abbaye bénédictine de Saint-Vanne mais, plus vraisemblablement, dans son erreur de Vedasti pour Vitoni, le scribe a été influencé par l'inscription des fêtes de Vedasti et Amandi au 26 octobre ou au 6 février dans les martyrologes (247).

Le nom spécifique des titulaires des deux monastères de Verdun a pu être méconnu du scribe.

Aucune mention de cette confraternité (248).

La fête de saint Remacle est inscrite dans un calendrier de SaintVanne au XIII e siècle (249).

Dans le lectionnaire de Saint-Vanne au XIIe siècle, on trouvc au 3 septembre (f. 67-68): In natale SS. Mansueti atque Remacli VIII lect. (250).

Aucune mention de reliques de saint Remacle à Saint-Vanne (251), ni de saint Vanne à Stavelot.

On notera cependant la présence de Richard de Saint-Vanne à la dédicace de l'autel de Sainte-Marie et de Saint-Maurice en 1046 à Sta-

(247) DuBois (J.), Le martyrologe d'Usuard. Texte et commentaire, Bruxelles, 1965, p. 176 (Subsidia HagIOGRAPHICA, no 40).

(248) Saint-Vanne est unie en confraternité avec plusieurs établissements : Saint-Bénigne de Dijon, Sainte-Marie de Luxembourg (1178), Sainte-Marie de Mouzon, Saint-Paul de Verdun (1325), Saint-Maur (1325)... Cf. LematTRE, Répertoire, op. cit., t. I, no 1666 ; Verdun, Bibliothèoue municipale, Manuscrit 7, f. 1-6v (XVe siècle) et Paris, BiblioTHĖQue NATIONALE, Nouv. Acq. Lat. 1417, f. 51-58 (Copie du XIXe siècle); ce dernier manuscrit, au folio $52 \mathrm{r}$, apporte des informations sur les règles générales de la confraternité : Pro universis in generali. Et quia nunquam humana infirmitas fraternitatis debitum persolvere potest sufficienciam, quod ignorantia vel negligentia in persolvendo hac derelinquimus, hac modo restauramus: ter in anno pro eis et pro omnibus fraternitatum nostranum defunctis, initio videlicet quadragesime, post octavas sanctonum Petri et Pauli, et post festivitatem Omnium Sanctorum, tricesinium celebramus hoc modo : septem missas et septem officia in conventu cantamus, $X X X$ diebus verbamen, $X X X$ diebus prebendam in refectorio, $X X X$ missas per ter fratres dividimus que ita sibi succedunt ut per $X X X$ dies numquam missa desit defunctis.

(249) Leroquais, Bréviaires, op. cit., t. IV, p. 313 : Verdun, Bibliothèque muniCIPALE, Manuscrit 111.

(250) VAN DER STRAETEN (J.), Les manuscrits hagiographiques, p. 106 (SUBSIDIA HAGIOGRAPHICA, $\mathrm{n}^{\circ}$ 56).

(251) Description du trésor par Dauphin (H.), Le bienheureux Richard, abbé de SaintVanne de Verdun, Louvain, 1945, p. 112-125. 
velot (252). Son disciple, Poppon, moine de Saint-Vanne, est commémoré («abbas ») dans l'obituaire de Saint-Vanne au 25 janvier (253).

Le nécrologe de Saint-Airy de Verdun ne porte aucune commémoration de moines de Stavelot-Malmedy (254).

Aucune relique de saint Airy à Stavelot. Par contre, Vanne et Airy sont présents dans les litanies du XIe siècle de Stavelot (255) et au calendrier du collectaire de Thierry de Stavelot (256).

Bien sûr nous ne pouvons a priori exclure que $S$. Vedasti en réfère à Saint-Vaast d'Arras et $S$. Theodorici à Saint-Thierry de Reims, mais qu'advient-il alors du toponyme Virdunensis?

Une solution maximaliste pourrait, elle aussi, être envisagée.

Dans l'hypothèse où Saint-Vaast d'Arras ferait aussi partie des fraternités de Stavelot, il faut relever :

qu'aucune mention réciproque de cette confraternité n'existe dans les sources d'Arras (257). Par contre Poppon est commémoré dans l'obituaire du XVIII ${ }^{e}$ siècle de l'abbaye Sanctus Poppo, primum fuit praepositus Sancti Vedasti, dein abbas ejusdem loci (258). Les inventaires du trésor de Saint-Vaast d'Arras de 1493 et 1544 (259) ne recensent pas de reliques stavelotaines. On notera cependant que la fête de saint Remacle est présente à Saint-Vaast aux XI ${ }^{e}$ et $X I V^{e}$ siècles (260).

(252) GeORGE, Les reliques de Stavelot-Malmedy, op. cit., p. 83 et 85.

(253) Bloch (H.), Die älteren Urkunden des Klosters S. Vanne, JAHRBUCH DER GESELLSCHAFT FUR LOTHRINGISCHE GESCHICHTE UND ALTERTUMSKUNDE, t. XIV, 1902, p. 136. Il ne faut pas non plus oublier les liens entre Liège et Verdun, dont les chapitres sont unis en confraternité, cf. AIMOND (Ch.), Le nécrologe de la cathédrale de Verdun, JAHRBUCH DER GESELLSCHAFT FÜR LOTHRINGISCHE GESCHICHTE UND ALTERTUMSKUNDE, t. XXI, 1909 et ROUSSEL, t. I.

(254) Crochet-Thery (M. -P.), Nécrologe ancien de Saint-Airy de Verdun, Mémoire inédit de l'Université de Nancy, 1971, mémoire aimablement communiqué par Monsieur Alain Marchandisse.

(255) COENS, op. cit., p. 238.

(256) HưYghebaert (N.), Notes sur un collectaire de l'abbaye de Stavelot, BulletiN DE LA Société D'ART \& D'HistoIre du DIOCĖSE dE LIĖGE, t. XXIII, 1947, p. 93-109. Sur la date et la destination de ce manuscrit, cf. MASAI, Manuscrits à peintures, op. cit., p. 184187 , à l'avis duquel nous nous rangeons entièrement.

(257) Arras est unie à Gisors (1024), cf. FaIDER, Mons, op. cit., no 518 p. 213.

(258) VAN Drival (E.), Notice sur le nécrologe de Saint-Vaast d'Arras, s. l. n. d. et IDEM, Nécrologe de Saint-Vaast, Arras, 1878, p. 11, 14, 433-435.

(259) Ed. de LoIsne, Bulletin archélogioue du Comité des TravauX histoRIQUES ET SCIENTIFIQUES, 1910, p. 205-219.

(260) LEROQUAIS (V.), Les psautiers manuscrits latins des bibliothèques publiques de France, 2 vol. et pl., Mâcon, 1940-41, t. I, p. 176 (Psautier du XI' siècle, DiJon, Bibliothèque Municipale, Manuscrit 30) et IDEM, Bréviaires, t. I, p. 40 (Bréviaire du XIVe siècle, ArRas, Bibliothèque municipale, Manuscrit 229) et p. 70. 
Dans l'hypothèse de Saint-Thierry de Reims, on notera : qu'aucune mention de cette fraternité n'existe dans le manuscrit 349 de la Bibliothèque Municipale de Reims qui répertorie beaucoup d'autres associations (261). La fête de saint Remacle est au calendrier de l'abbaye Saint-Thierry de Reims depuis le XIIe siècle (262). En 1733, des reliques de saint Poppon sont envoyées de Stavelot à SaintThierry (263).

58. WAULSORT, Sainte-Marie [16]

Cette abbaye bénédictine fut en relations étroites avec Poppon $(+1048)$ et Wibald $(\dagger 1158)$; certains de ses abbés sont originaires de Stavelot comme Lambert ( $t$ après 1070) ou Robert ( +1174$)$ (264). Pas de mention réciproque de la confraternité et absence d'obituaire (265).

Saint Remacle est inscrit au calendrier d'un psautier d'Hastière (ca. 1050-1070) et dans les litanies, ainsi que dans un missel du XVI ${ }^{e}$ siècle à l'usage de l'abbaye. Une relique du saint était conservée dans un phylactère mosan (ca. 1160) qui en porte inscription et effigie; d'après l'inventaire de François Mirwart de 1615, on garde au trésor « une pièce de la chasuble de S. Remacle » (266).

Le 2 août 1628, Dom Pierre Poilvache, abbé de Waulsort, reçut un fragment de côte de saint Poppon (267).

(261) LematrRe, Répertoire, op. cit., t. II, n 1705, p. 735.

(262) DuboIs (J.), Le calendrier et le martyrologe de l'abbaye de Saint-Thierny au Moyen Age, ACtes du Colloque international d'Histoire monastique. Saint-Thiern, une abbaye du $V^{e}$ au $X X^{e}$ siècle, Reims, 1976, publié en 1979, p. 199 et 222.

(263) Almanach Matot-Braine des Trois Départements de la Marme, de l'Aisne et des Ardennes, 1931, p. 336-338, et repris par LEGRAND (W.), Notes sur le culte de saint Poppon, abbé de Stavelot, Chronique Archéologique du Pays De Liège, 1943, p. 26. Poppon a été moine à Saint-Thierry avant sa désignation par l'empereur à Stavelot.

(264) LAHAYE (L.), Etude sur l'abbaye de Waulsort de l'Ordre de S. Benô̂t, Liège, 1889, et DESPY (G.), Les chartes de l'abbaye de Waulsort. Etude diplomatique et édition critique, t. I (946-1199), Bruxelles, 1957.

(265) Une seule association spirituelle est répertoriée par L. Lahaye (op. cit., p. 275 et 327) : en 1157, avec Saint-Jean l'Évangéliste à Liège.

(266) BAIX (Fr.), Saint Remacle dans le Namurois, op. cit., p. 183 et IDEM, Saint Remacle. Culte \& reliques (II), p. 25; DIDIER (R.), A propos du «Beryl $»$ de Lothaire et d'orfevrerie des XII' et XIII' siècles provenant de l'abbaye de Waulsort, NOTES WAULSORTOISES rassemblées par WAYENS (A.), t. V, Waulsort, 1987, p. 208-251, et GEORGE, Les reliques de Stavelot-Malmedy, op. cit..

(267) LEGRAND, op. cit., p. 25. 


\section{LES ARCHIVES DE L’ÉPOQUE MODERNE}

D'autres documents apportent quelques informations sur le réseau de fraternité de Stavelot : tout d'abord un dossier spécial conservé aux Archives de l'Etat à Liège (Fonds de Stavelot-Malmedy, I, 378); il contient des renouvellements de fraternité essentiellement d'époque moderne : Saint-Maximin de Trèves (1552); Saint-Laurent de Liège (1574); Saint-Hubert en Ardennes (1628 et 1728); et Saint-Jacques de Liège (1574 et 1635). C'est vraisemblablement de ce dossier que s'est servi Dom Hubert Burnenville (268) qui cite aussi le Val-Saint-Lambert en 1650.

La copie $C$ de la liste des fraternités de Stavelot (Annexe 1) comporte une note complémentaire, d'une écriture plus récente, que nous éditons ci-dessous en annexe 4. Il s'agit des principaux établissements que Stavelot contactera par «brefs » c'est-à-dire par lettres de faire-part annonçant le décès d'un frère (269).

On y notera la mise en évidence de Liège, Trèves et Cologne, les trois cités épiscopales les plus proches. On remarquera l'apparition de Brauweiler dont nous avions signalé l'absence dans la liste précédente.

(268) LIEGE, ARChIVES de L'ETAT, Fonds de Stavelot-Malmedy, I, 307, p. 325-326 ; cf. HansotTe (G.), Inventaire des archives de l'abbaye et de la principauté de Stavelot-Malmedy, Bruxelles, 1961.

(269) Lemaitre, Mourir à Saint-Martial, op. cit., p. 324 sv.. 


\section{CONCLUSIONS}

A Stavelot et à Malmedy, principalement au XII ${ }^{\text {e }}$ siècle, les confraternités se réaffermissent et se multiplient. La fraternité apporte « un soutien dans la vie et un secours après la mort » (270), une «assurance pour l'au-delà » (271). Comme l'écrit saint Benoît au chapitre 72 de sa Règle : «[...] les moines [...] s'honoreront mutuellement avec prévenance [...] nul ne recherchera ce qu'il juge utile pour soi, mais bien plutôt ce qui l'est pour autrui; ils s'accorderont une chaste charité fraternelle [...] » (272). La Règle de saint Benoît prescrit des mesures précises pour l'accueil des moines et pour leurs déplacements (273). Cet esprit de famille, cher au père du monachisme, soustend la formation des fraternités qui prescrivent une «entraide spirituelle durant la vie, [une] prière pour les âmes après la mort » (274). La Societas et fraternitas casse l'isolement et atteste un besoin de contacts; les relations intermonastiques se sont développées, peut-être favorisées par les mouvements de réforme perceptibles en bien des cas. Cette étape est préalable à la constitution de groupements organisés. A propos des fraternités, Dom Dubois ne parlait-il pas d'« essai de regroupement avant la constitution des ordres » (275)?

(270) Duhr (J.), La confrénie dans la vie de l'Eglise, REVue D'Histoire eCCLESIASTIQUE, t. XXXV, 1939, p. 451, et surtout HUYGHEBAERT (N.), Les documents nécrologiques, Turnhout, 1972 (Typologie des Sources du Moyen Age occidental, Fasc. 4), p. 17-21.

(271) Lemaitre, Mourir à Saint-Martial, op. cit., p. 378.

(272) Nous donnons ici la traduction française établie en synoptique dans Règle de saint Benoit. Texte latin, traduction et concordance par Ph. SCHMITZ, Introduction par A. Borias, $5^{\mathrm{c}}$ édition, Turnhout, 1987. Les extraits donnés ci-dessous proviennent du même ouvrage.

(273) Au c. 58 : De disciplina suscipiendorum fratrum (la manière de recevoir les frères). C. 58, 17 Suscipiendus autem... Avant d'être reçu, il promettra donc publiquement, dans l'oratoire, stabilité, vie religieuse et obéissance en la présence de Dieu et de ses saints [...] A dater de ce jour, on le tiendra pour membre de la communauté. C. 61 De monachis peregrinis qualiter suscipiantur (Comment recevoir les moines étrangers). Si quis monachus peregrinus... Si un moine étranger vient d'une région lointaine et veut demeurer, comme hôte, dans le monastère, on le recevra autant de temps qu'il le désire, pourvu qu'il se contente de la vie qu'on y mène, et ne trouble pas la communauté par ses vaines exigences, mais simplement s'accommode de ce qu'il trouve [...]. Si, dans la suite, il y veut fixer sa stabilité, on ne s'y refusera point [...].

(274) DUHR, op. cit., p. 456.

(275) Discussion de l'article de Falkenstein, Le calendrier, op. cit., p. 28. 
Les actes de fraternité s'échangent principalement au début des XII $^{e}$-XIII ${ }^{e}$ siècles, selon un modèle bien connu (276). La pratique se prolonge jusqu'à la fin de l'Ancien Régime; les droits et avantages essentiellement spirituels au départ évoluent et s'accompagnent d'avantages matériels.

Naguère les idées semblaient bien arrêtées sur l'inutilité d'un recensement exhaustif des confraternités. Léopold Delisle n'écrivait-il pas : «Il serait impossible et sans intérêt de les énumérer» (277) ? Dom Philibert Schmitz était plus nuancé : «Il n'y a aucun intérêt à en énumérer des exemples. Il suffit, pour montrer la vogue dont elles jouissent, de citer Saint-Germain-des-Prés qui était associé à 82 monastères et Reichenau à plus de 100 » (278). La recherche historique a bien évolué depuis, et Pierre Riché n'hésitait pas, il y a quelques années, à souhaiter l'élaboration d'un «volume de cartes qui permettrait de voir les liens qui existent entre les différents centres religieux » (279).

A titre de comparaison 37 communautés sont liées à Saint-Martial de Limoges ou à Solignac, et 82 à La Sauve-Majeure (280).

Dans le cas qui nous occupe, au-delà des liens spirituels, se dégagent des éléments importants dans la recherche d'autres informations qu'elles soient d'ordre économique, artistique, culturel ou cultuel. La confraternité transcende le concept de « réseau monastique » dont la base est constituée par la "réforme » (281); elle sort aussi des limites de l'ordre bénédictin - même s'il semble en constituer la base puisque nous trouvons une abbaye cistercienne et des chapitres séculiers et réguliers unis à Stavelot-Malmedy. A l'origine, il n'est pas sûr qu'une tentative de congrégation se soit formée; par la suite les liens sont établis en dehors de l'ordre bénédictin.

(276) La trace la plus ancienne de liens nécrologiques remonte toutefois à la liste des moines de Malmedy-Stavelot à Remiremont aux $\mathrm{IX}^{\mathrm{e}}-\mathrm{X}^{\mathrm{c}}$ siècles. Leur modèle correspond en gros à celui défini par DELISLE (L.), Des monuments paléographiques concernant l'usage de prier pour les morts, BIBLIOTHĖQue DE l.ECOLE DES ChARTES, $2^{c}$ série, $t$. III, Paris, 1846, p. 367, repris par DOPPLER (P.), Obituaire de l'église collégiale, libre et impériale de Saint-Senvais à Maestricht commencé vers 1294, PUBLICATIONS DE LA SOCIÉTÉ HISTORIQUE \& ARChEOlOgIQUe DANS LE LIMBOURG, t. XLVII, 1911, p. XXVII.;

(277) DELISLE, op. cit., p. 366.

(278) Schmitz (Ph.), Histoire de l'Ordre de S. Benoît, t. I, Maredsous, 1940, p. 301.

(279) Discussion de l'article de Falkenstern, Le calendrier, op. cit., p. 28.

(280) LematTre, Mourir à Saint-Martial, op. cit., p. 368.

(281) Cf. Naissance et fonctionnement des réseaux monastiques et canoniaux, Actes du premier colloque international du C.E.R.C.O.M, Saint-Etienne, 16-18 septembre 1985, SaintEtienne, C.E.R.C.O.R., 1991. 
Par l'étude des confraternités de Stavelot-Malmedy, on perçoit exactement la place de l'abbaye et ses contacts avec le monde extérieur. Stavelot et Malmedy se trouvent ainsi « au centre d'une immense famille spirituelle ", pour reprendre une belle expression d'Henri Platelle (282).

Les liens n'étaient pas permanents, ils se distendaient sous l'effet de la distance et des aléas puisque l'on constate qu'il fallait de temps à autre les renouveler (283). L'ardeur, le dynamisme ou la bonne volonté d'un abbé sont souvent le moteur à la base des rapprochements (284). Aussi à l'instar des constatations déjà faites à propos des reliques des saints, serions-nous en droit d'intituler une bonne partie de ces recherches « Poppon, Wibald ou Erlebald et les confraternités de l'abbaye bénédictine de Stavelot-Malmedy » (285).

(282) Platelle, Les relations entre Saint-Amand, op. cit., p. 362.

(283) Cf. R.-H. BAutier dans la discussion de l'article de FALKENSTEIN, Le calendrier, op. cit., p. 27.

(284) La même remarque peut être faite pour Saint-Remi de Reims où la majorité des textes encore existants appartient aux abbés Odon (1118-1151) et Hugues (1151-1162), cf. Falkenstein, Le calendrier, op. cit., p. 23.

(285) Au terme de cet article, nous remercions très vivement les Commissaires chargés par la Commission Royale d'Histoire de l'examen du texte, Messieurs les Professeurs Adriaan-E. Verhulst, Jean-Jacques Hoebanx, Ludo Milis, André Joris, ainsi que feu Monsieur le Professeur Georges Hansotte qui nous avait encouragé à déposer notre manuscrit.

Notre gratitude va également à Monsieur le Professeur Jean-Louis Kupper et Monsieur Jan Gerchow pour les remarques dont ils ont bien voulu nous faire part. Monsieur le Professeur Jean-Jacques Hoebanx a procédé à l'ultime révision du manuscrit. 


\section{ANNEXE}

\section{1}

\section{Liste de confraternités de Stavelot}

$$
\text { [(1202-1218)-1338] }
$$

\section{A. Original : perdu.}

Si nous inclinons à croire qu'un original a existé, nous reconnaissons toutefois qu'il n'est pas possible de trancher la question. Joseph Halkin et le chanoine Ruland pensaient que la liste avait été directement transcrite dans la Bible de Stavelot et la considèrent comme l'original; c'est d'elle en tout cas que dérivent toutes les copies, ce qui laisserait à penser que l'original était peut-être déjà perdu au $\mathrm{XV}^{*}$ siècle.

$B$. CopIE : d'une écriture du XIVe siècle, dans le second volume de la Bible de Stavelot (LONDRES, BRITISH LIBRARY, Add. 28107, f. 239v)

C. Copie d'après $B$ : du XVe siècle dans ARChives de L'ÉtAT A Liége, Fonds de Stavelot-Malmedy, I, 378, sans foliotation.

$D$. CopIE d'après $B:$ du XVIe siècle dans IBIDEM

$E$. COPIE d'après $B:$ du XVI ${ }^{e}$ siècle dans IBIDEM, I, 373, f. $70 \mathrm{r}$ et v.

EDITION : HR 1700.

Ecclesie de fraternitate chenobii S. Remacli Stabulensis ordinis Sancti Benedicti Leodiensis Dyocesis

S. Petri Malmundariensis [34 (286)]

S. Petri Solempniacensis [52]

S. Eligii Noviomensis [42]

S. Petri Corbeycensis [12]

S. Lamberti Leodiensis [29]

S. Martini Leodiensis [31]

S. Jacobi in Insula Leodiensis [28]

S. Laurentii juxta muros Leodiensis [30]

S. Egidii in Pullo monte [27]

S. Sepulchri juxta Hoyum [24]

S. Perpetui in Dyonanto [15]

S. Huberti in Arduenna [49]

S. Hadelini in Cella [8]

S. Johannis Baptiste Florinensis [17]

(286) Le numéro entre parenthèses renvoie ci-dessus à l'identification dans notre commentaire, où nous avons réorganisé la liste par ordre alphabétique ; la localisation des lieux est faite ci-dessous, en parallèle avec les cartes de l'article. 
Vallis Sancti Lamberti [55]

S. Marie Walsiodorensis [58]

S. Petri in Malonia [35]

S. Petri in Lobiis [32]

S. Petri Gemblacensis [19]

$\mathrm{S}$. Eugenii in Bromio [5]

$\mathrm{S}$. Trudonis in Hasbania [50]

S. Begge Andennensis [2]

S. Johannis Baptiste in Borceto [7]

S. Cornelii Indensis [13]

S. Pantaleonis Coloniensis [10]

S. Martini Coloniensis [9]

S. Heriberti Tuiscii [14]

S. Suiberti Werdensis [25]

S. Goaris supra Renum [48]

S. Mychaelis Sigiberdensis [51]

S. Petri Treverensis [54]

S. Maximini Treverensis [53]

S. Salvatoris Prumiensis [44]

S. Wilebrordi in Epternaco [16]

Ad Lacum [26]

Lusselburgensis [33]

S. Pauli in Paldeburna [43]

S. Remigii Remensis [46]

S. Nichasii Remensis [45]

S. Gorgonii Gorgiensis [20]

S. Petri Herlimarcinensis [22]

S. Dyonisii in Brukherout [6]

S. Petri in Gandavo [18]

S. Clementis Metensis [37]

S. Martini Metensis [38]

S. Symphoriani Metensis [39]

S. Vincentii Metensis [40]

S. Arnulphi Metensis [36]

S. Petri in Alto monte [21]

S. Amandi in Peveria [47]

S. Cornelii Compendiensis [11]

S. Vedasti et Amandi Virdunensis [56]

$S$. Theodorici in Insula Virdunensis [57]

Haffligensis [1]

S. Marie Bellifageti [3]

Montis Sancti Cassini [41]

Quibus addi debent (287)

(287) Ces trois dernières lignes [Quibus... Bermardfaing] ne figurent que dans $E$. 
Ecclesia S. Catharinae Hufaliziae [23]

Ecclesia S. Mariae V. in Bernardfaing [4]

L'abbé Arnoul de Berct et les moines de Saint-Jacques de Liège accordent la confraternité à l'abbé Jaspar de Stavelot-Malmedy

\section{9 mars 1479}

A. Original: Archives de l'État a Liège, Fonds de Stavelot-Malmedy, Chartes, $n^{\circ} 252$ (255)(anc. R. 1. 12). Parchemin, encre brune. Le parchemin mesure H. 189 X L. $363 \mathrm{~mm}$. ; il est replié en bas sur toute sa longueur d'une bande de $54 \mathrm{~mm}$, de sorte que le texte ne se déroule que sur une hauteur de $81 \mathrm{~mm}$. et sur toute la longueur. Aucune trace de sceau. Au verso inscriptions séparées : Confraternitas cum monasterio Sancti Jacobi Leodiensis. Abbas Jaspar fit particeps suffragiorum omnium monasterii Sancti Jacobi Leodiensis

ANALYSE : HR 829 (analyse, sans édition ni identifications).

Berlière, Saint-Jacques, Monasticon, op. cit., p. 23

Arnoldus de Berct (288), divina permissione abbas totiusque conventus monasterii Sancti Iacobi Leodiensis ordinis sancti Benedicti, reverendus in Christo, / presbiteri et domino Jaspari Stabulensis ac Malmundariensis monasteriorum abbati, salutem a Domino. Bonis profari sempiternis, prius vestre devocionis / affectus quam ad nostrum monasterium gerit exigencia digna, requivit ut vestram personam ad nostram fraternitatem suscipiamus. Praeterea nos / vestris devocionibus ac piis peticionibus satisfacere cupiens, vos ad fraternitatem nostram et ad universa et singula fratrum nostrorum suffragia / in vita recepimus, pariter et in morte plenam vobis et specialem participacionem omnium carissimam et spiritualium bonorum, videlicet missarum, / oracionum, officiorum divinorum, praedicacionum, lectionum, jejuniorum disciplinarum, vigiliarum ceterarumque bonorum tenore praesentium generose conferentes / quae per nos fieri dederit Auctor omnium bonorum, Dei Filius, ut multiplici suffragiorum adiutus [...] sidio et hic aucmentum generalem et in futuro [...] (289) / eterne vite presentia poss[et fa]ciendum de gratia speciali quaecum obitus vester quem Deus felicem faceat, nobis per presentes fuerit nunciatus [...] (290) / sacerdos

(288) Biographie par U. Berlière, Saint-Jacques, Monasticon, op. cit.. On notera que l'abbé conclut une confraternité avec Saint-Martin de Tournai le 30 avril 1475 (DEVILlers (L.), Lettres de confratemité de l'abbaye de S. Martin de Toumai (1449-1713),

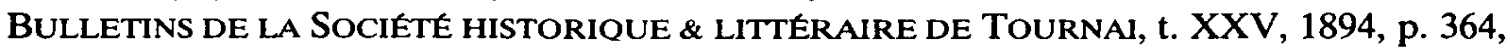
aimablement transmis par Monsieur Jacques Pycke).

(289) Parchemin abîmé.

(290) Idem. 
pro vestra salute, tres missas, singuli autem alii non sacerdotes tres vigilias. In cuius rei testimonium presentem litteram nostris / sigillis fecimus communiri. Anno domini millesimo $\mathrm{CCCC}^{\text {mo }}$ septuagesimo nono mensis marcii die decima nona.

Titulus de l'abbaye de Stavelot-Malmedy sur le rouleau mortuaire de Hugues de Maumont, abbé de Solignac († 1240)

A. Original: Archives Départementales de la Haute-Vienne, Cote 6 H 6. Dixième fragment, $X$ (feuille 22) : $47 \times 22 / 23 \mathrm{~cm}$. Au recto, dernier titre (début).

B. CoPIE : du XVII ${ }^{e}$ siècle par Dom Claude EstIennot, Antiquitates in dioecesi Lemovicensi benedictinae, PARIS, BIBLIOTHĖOUE NATIONALE, Manuscrit latin 12748 , f. 261-271

Étrion : RIVAIN (C.), Le rouleau des mons de l'abbaye de Solignac. Texte \& commentaire, Bulletin de LA SOCIÉtE ARChÉlogioue \& Historioue du LiMOUSin, t. XXVI, 1878 , p. $327-367$, et à part, Limoges, 1879,43 p. (Ici p. 31)

ANAL YSE : LEMAiTRE, Les documents nécrologiques de Solignac, op. cit., p. 401.

Tous ces renseignements ainsi que l'édition suivante nous ont très aimablement été transmis par Jean-Loup Lemaître avec les remarques suivantes : « La partie du rouleau sur laquelle se trouvait cette pièce de vers n'existe plus. Obligé de citer ces vers d'après le texte défiguré que nous a transmis Dom Estiennot, nous leur avons fait subir au préalable quelques corrections indiquées par le sens. Ainsi au cinquième vers, nous avons dû restituer : Aeterne lucis, au lieu de Aetema succis, etc. ".

Titulus Beati Remacli episcopi et confessoris in Ardenna...Orate pro nostris. In die beati Bonefacii (291), fuit apud nos Johannes roligifer : videlicet pro Arnulfo, Bonefacio, Garsilio, Goberto, sacerdotibus, pro Cunone converso.

Titulus Sancti Petri in Mamundario.

Abbas Ugo decus, hac est de carne solutus,

Quem non Tartareus turbo premat, imo secutus

Nostre carnis iter, Abrahe gremio societur.

Cum superis pariter vivens vita satietur.

Aeterne lucis niteat fulgore superne,

Aeternique ducis vigeat dulcore superne.

Sol sine nube die sit, nocte quies sine poena :

Coelica pax, requies huic detur et horrea (?) plena.

(291) 5 juin. 
Liste des «brefs » de Stavelot au XVII siècle

$A$. Original : perdu. Il s'agit de renseignements ajoutés à la suite de la liste des confraternités de Stavelot éditée ci-dessus (Copie $C$ ); la même remarque que pour l'annexe I prévaut quant à l'existence ou non d'un original.

Ces brefs nous indiquent les confraternités existantes et nous ne donnerons des commentaires que sur les liens nouveaux.

B. CopIE : d'une écriture du XVII' siècle, LiEge, Archives de l'ETAT, Fonds de Stavelot-Malmedy, I, 378.

Que sint loca precipua ad que pro tempore mittenda forent brevia pro fratre defuncto./

Primo ad fratres nostros Malmundarienses (292),/ ad Sanctum Hubertum in Arduenna (293),/ ad Sanctum Cornelium (294),/ ad Sanctum Remigium prope Rupefortem (295)./

Apud Leodium:/ad Sanctum Iacobum (296),/ ad Sanctum Laurentium (297),/ ad Carmelitas (298),/ ad Cruciferarios (299),/ ad Chartusienses (300),/ ad Fratres Minores de observantia,/ ad alios Minores,/ ad Predicatores Augustinenses (301)./

(292) Malmedy (Liège, Verviers, Malmedy).

(293) Saint-Hubert (Luxembourg, Neufchâteau, Saint-Hubert).

(294) Cornelimünster (R.F.A., Rhénanie-Westphalie).

(295) Abbaye cistercienne de Saint-Remi à Rochefort (Namur, Dinant, Rochefort); cf. Berliere (U.), Abbaye de Saint-Remy, Monasticon belge, t. I, Provinces de Namur et de Hainaut, 1890, p. 87-91 : aucun lien particulier n'a été répertorié ; relevons-y seulement, en pure hypothèse sur ses origines, un abbé du nom de Bernard de Malmedy, ca. 1559.

(296) Abbaye de Saint-Jacques à Liège (Liège, Liège, Liège).

(297) Abbaye de Saint-Laurent à Liège (Liège, Liège, Liège).

(298) A Liège, il existe un couvent de Carmélites à Saint-Léonard dès le $\mathrm{XV}^{\mathrm{c}}$ siècle (Cf. Gobert (Th.), Les rues de Liège, réimpr. anast. de l'éd. originale de 1924-1929, Bruxelles, 1976, t. VII, p. 256-260) et un autre de Carmélites déchaussées au Potay (IDEM, t. IX, p. 548- 556).

(299) Liège, Couvent des Croisiers; cf. van de Pasch (A.), MONASticon belge, t. II, p. 415-422, qui mentionne seulement une fraternité unissant les Croisiers à SaintJacques.

(300) Liège, Chartreuse des Douze Apôtres, cf. Stiennon (J.), Monasticon belge, t. II, 1955, p. 489-526. Saint Remacle est inscrit au calendrier d'un graduel de la Chartreuse de 1367 (IDEM, p. 495).

(301) On distinguera chronologiquement les Frères Mineurs Conventuels installés à Liège depuis le XIII ${ }^{e}$ siècle, les Frères Mineurs Observants et Récollets, et les Ermites de Saint-Augustin à partir du XVe siècle, cf. BRAGARD (R.), Les provinces religieuses des Ordres mendiants dans la principauté de Liège, BULlETIN DE LA COMMISSION ROYALE D'HistolRe, t. CXVII, 1952, p. 231-397. 
Item ad monasterium Lobbiensis (302),/ ad monasterium Gemblacense (303)./

Apud Treverim (304): / ad Sanctum Mathiam,/ ad Sanctam Mariam,/ ad Sanctum Maximianum,/ ad Sanctum Martinum./

Item ad monasterium de Colonia (305), / ad Sanctum Martinum maiorem,/ ad Sanctum Panthaleonem,/ ad Sanctum Heribertum apud Tuiensis (306)./ Item ad monasterium de Werdena (307),/ ad monasterium Bruwilarenses (308), / ad monasterium de Lacu (309).

\section{LOCALISATION DES NOMS DE LIEUX}

L'identification des toponymes est faite selon les Instructions de la Commission Royale d'Histoire, c'est-à-dire que l'on trouvera entre parenthèses le nom du pays si ce n'est pas la Belgique ; province, département ou land ; l'arrondissement et la commune pour la Belgique. Pour caractériser le type d'établissement religieux sur nos cartes, nous avons aligné nos sigles sur ceux des travaux de Jean-Loup Lemaître.

\section{ACTES DE CONFRATERnite}

\section{A. Stavelot-Malmedy}

1. Corvey (R.F.A., Rhénanie-Westphalie)

2. Cornelimünster (R.F.A., Rhénanie-Westphalie)

(302) Lobbes (Hainaut, Thuin, Lobbes).

(303) Gembloux (Namur, Namur, Gembloux).

(304) Trèves (R.F.A., Rhénanie-Palatinat). Suivent les noms des quatre abbayes bénédictines.

(305) Cologne (R.F.A., Rhénanie-Westphalie). Suivent les noms des deux abbayes mentionnées plus haut.

(306) Deutz (R.F.A., Rhénanie-Westphalie).

(307) Kaiserswerth (R.F.A., Rhénanie-Westphalie).

(308) Brauweiler (R.F.A., Rhénanie- Wetsphalie).

(309) Laach (R.F.A., Rhénanie-Palatinat). 


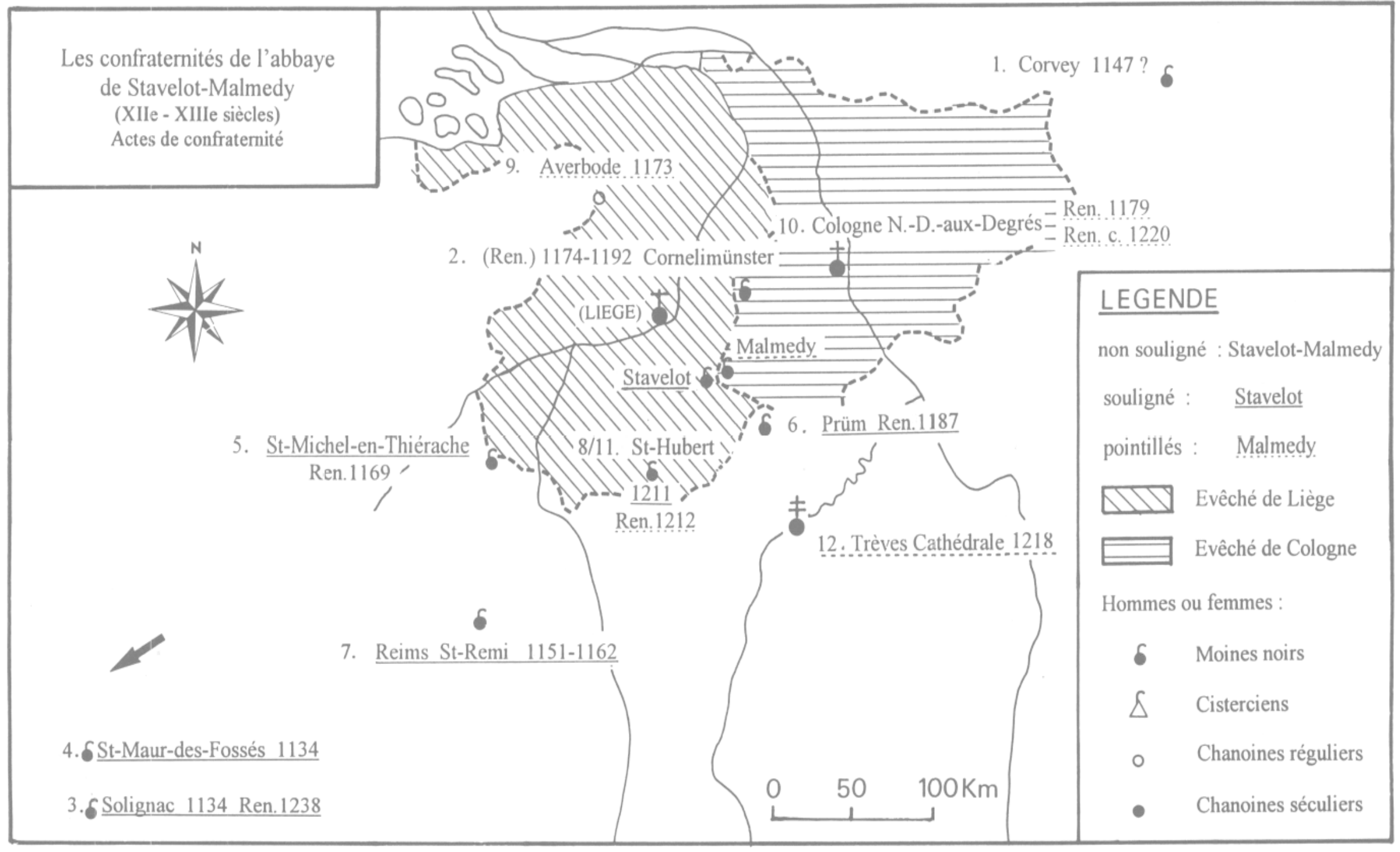




\section{B. Stavelot}

3. Solignac (France, Haute-Vienne)

4. Saint-Maur-des-Fossés (France, Val-de-Marne)

5. Saint-Michel-en-Thiérache (France, Aisne)

6. Prüm (R.F.A., Rhénanie-Palatinat)

7. Reims, Saint-Remi (France, Marne)

8. Saint-Hubert (Luxembourg, Neufchâteau, Saint-Hubert)

\section{MALMEDY}

9. Averbode (Brabant, Louvain, Scherpenheuvel-Zichem)

10. Cologne, Notre-Dame-aux-Degrés (R.F.A., Rhénanie-Westphalie)

11. Saint-Hubert (Luxembourg, Neufchâteau, Saint-Hubert)

12. Trèves (R.F.A., Rhénanie-Palatinat)

II. LISTE DES CONFRATERNITÉS DE STAVELOT [(1202-1218) - 1338]

1. Affligem (Brabant, Halle-Vilvoorde, Hekelgem)

2. Andenne (Namur, Namur, Andenne)

3. Beaufays (Liège, Liège, Chaudfontaine)

4. Bernardfagne (Liège, Huy, Ferrières)

5. Brogne (Namur, Namur, Mettet)

6. Broqueroie (Hainaut, Mons, Mons)

7. Burtscheid (R.F.A., Rhénanie-Westphalie)

8. Celles (Namur, Dinant, Houyet)

9-10. Cologne (R.F.A., Rhénanie-Westphalie)

11. Compiègne (France, Oise)

12. Corbie / Corvey (R.F.A., Rhénanie-Westphalie)

13. Cornelimünster (R.F.A., Rhénanie-Westphalie)

14. Deutz (R.F.A., Rhénanie-Westphalie)

15. Dinant (Namur, Dinant, Dinant)

16. Echternach (Grand-Duché de Luxembourg)

17. Florennes (Namur, Philippeville, Florennes)

18. Gand (Flandre Orientale, Gand, Gand)

19. Gembloux (Namur, Namur, Gembloux)

20. Gorze (France, Moselle)

21. Hautmont (France, Nord)

22. Helmarshausen (R.F.A., Hesse)

23. Houffalize (Luxembourg, Bastogne, Houffalize)

24. Huy (Liège, Huy, Huy)

25. Kaiserswerth (R.F.A., Rhénanie-Westphalie) 


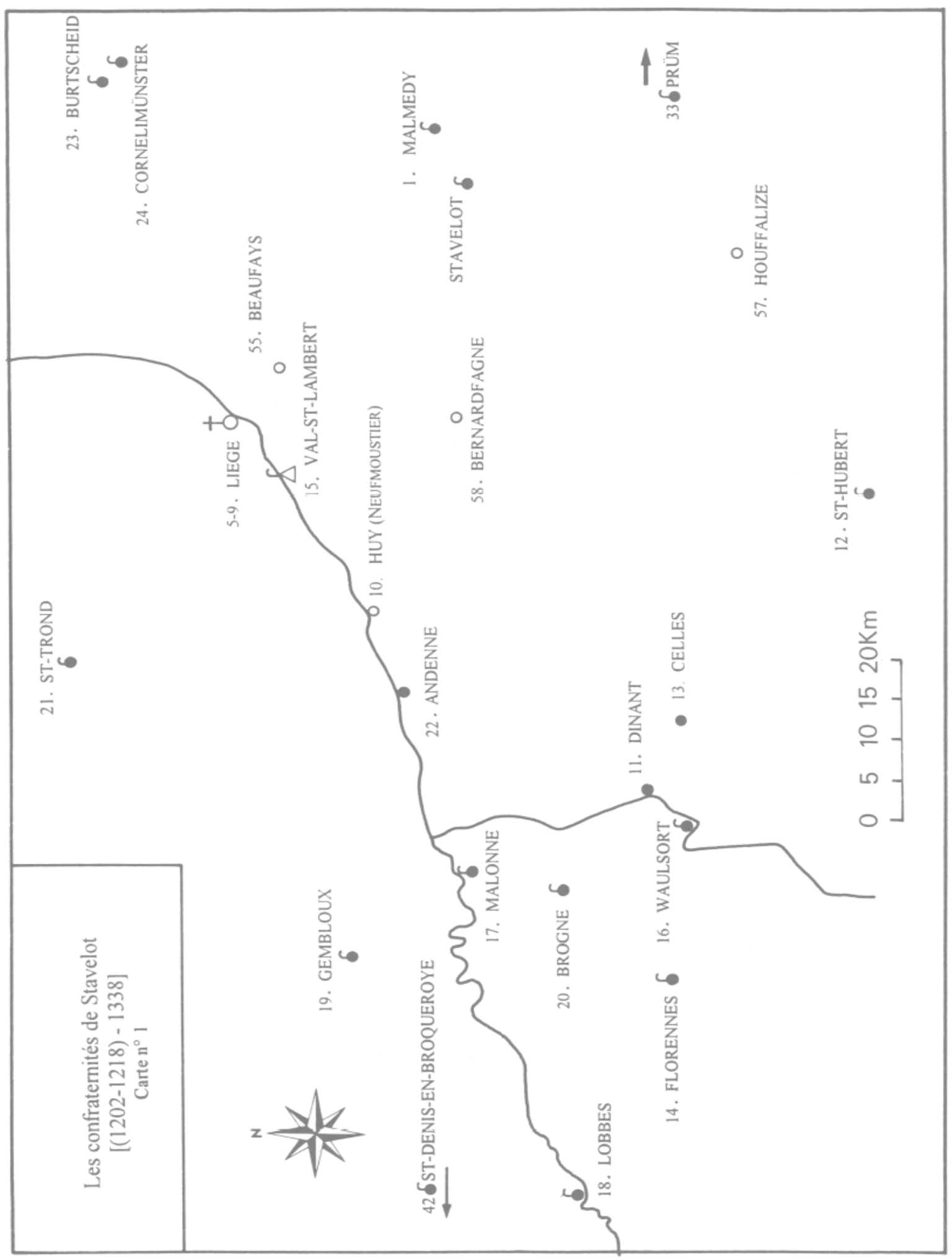

Les numéros portés sur les deux cartes (p. 167-168) respectent l'ordre d'énumération des confraternités dans les manuscrits et non l'ordre alphabétique des établissements rétabli pour le commentaire (cf. Annexe 1). 


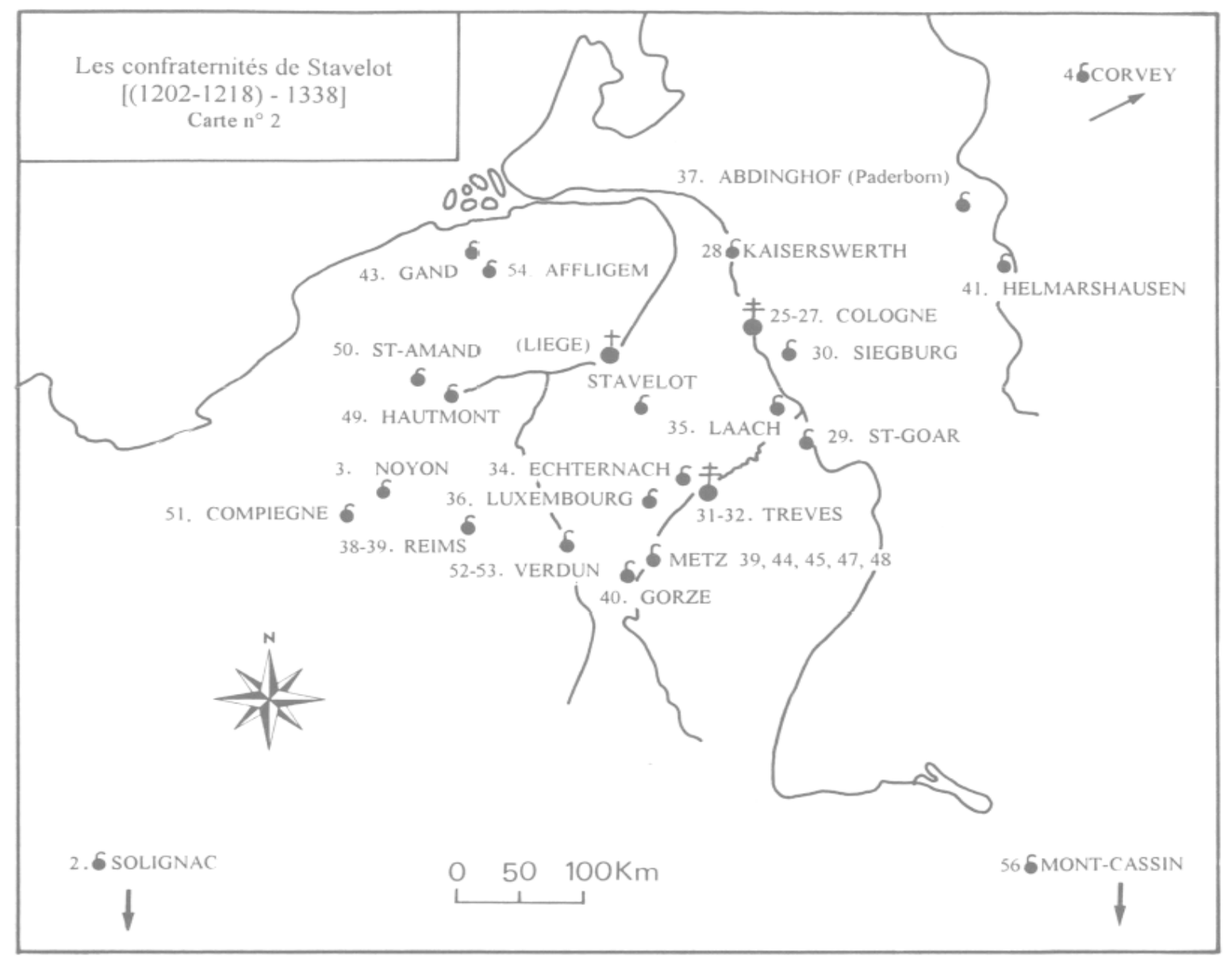

26. Laach (R.F.A., Rhénanie-Palatinat)

27-31. Liège (Liège, Liège, Liège)

32. Lobbes (Hainaut, Thuin, Lobbes)

33. Luxembourg (Grand-Duché de Luxembourg)

34. Malmedy (Liège, Verviers, Malmedy)

35. Malonne (Namur, Namur, Namur)

36-40. Metz (France, Moselle)

41. Mont-Cassin (Italie, Latium, pr. Frosinone)

42. Noyon (France, Oise)

43. Paderborn (R.F.A., Rhénanie-Westphalie)

44. Prüm (R.F.A., Rhénanie-Palatinat)

45-46. Reims (France, Marne)

47. Saint-Amand-les-Eaux (France, Nord)

48. Saint-Goar (R.F.A., Rhénanie-Westphalie)

49. Saint-Hubert (Luxembourg, Neufchâteau, Saint-Hubert)

50. Saint-Trond (Limbourg, Hasselt, Saint-Trond)

51. Siegburg (R.F.A., Rhénanie-Westphalie)

52. Solignac (France, Haute-Vienne) 
53-54. Trèves (R.F.A., Rhénanie-Palatinat)

55. Val-Saint-Lambert (Liège, Liège, Seraing)

56-57. Verdun (France, Meuse)

58. Waulsort (Namur, Dinant, Hastière). 